\title{
Geolectric field measurement, modelling and validation during geomagnetic storms in the UK
}

\author{
Ciarán D. Beggan*, Gemma S. Richardson, Orsi Baillie, Juliane Hübert, and Alan W. P. Thomson \\ British Geological Survey, Research Ave South, Riccarton, EH14 4AP Edinburgh, UK
}

Received 26 June 2020 / Accepted 25 May 2021

\begin{abstract}
Significant geoelectric fields are produced by the interaction of rapidly varying magnetic fields with the conductive Earth, particularly during intense geomagnetic activity. Though usually harmless, large or sustained geoelectric fields can damage grounded infrastructure such as high-voltage transformers and pipelines via geomagnetically induced currents (GICs). A key aspect of understanding the effects of space weather on grounded infrastructure is through the spatial and temporal variation of the geoelectric field. Globally, there are few long-term monitoring sites of the geoelectric field, so in 2012 measurements of the horizontal surface field were started at Lerwick, Eskdalemuir and Hartland observatories in the UK. Between 2012 and 2020, the maximum value of the geoelectric field observed was around $1 \mathrm{~V} / \mathrm{km}$ in Lerwick, $0.5 \mathrm{~V} / \mathrm{km}$ in Eskdalemuir and $0.1 \mathrm{~V} / \mathrm{km}$ in Hartland during the March 2015 storm. These long-term observations also allow comparisons with models of the geoelectric field to be made. We use the measurements to compute magnetotelluric impedance transfer functions at each observatory for periods from 20 to $30,000 \mathrm{~s}$. These are then used to predict the geoelectric field at the observatory sites during selected storm times that match the recorded fields very well (correlation around 0.9 ). We also compute geoelectric field values from a thin-sheet model of Britain, accounting for the diverse geological and bathymetric island setting. We find the thin-sheet model captures the peak and phase of the band-passed geoelectric field reasonably well, with linear correlation of around 0.4 in general. From these two modelling approaches, we generate geoelectric field values for historic storms (March 1989 and October 2003) and find the estimates of past peak geoelectric fields of up to $1.75 \mathrm{~V} / \mathrm{km}$ in Eskdalemuir. However, evidence from high voltage transformer GIC measurements during these storms suggests these estimates are likely to represent an underestimate of the true value.
\end{abstract}

Keywords: geoelectric field / magnetotellurics / thin-sheet model / conductivity / geomagnetically induced currents

\section{Introduction}

During severe space weather events, the Earth's magnetic field can change rapidly with large variations in the order of thousands of nT (e.g. Hapgood, 2019). The time variations of the externally-produced magnetic field induce electric fields in the conductive ground, whose magnitude and spatial scale depend on the underlying electrical conductivity structure. For long period variations (hundreds to thousands of seconds) in resistive geology, the skin-depth is large $(10-100 \mathrm{~km})$ and the magnetic field generates a large geoelectric field. Short period variations (tens of seconds) of the magnetic field in a conductive subsurface have shallow skin depths $(0.1-1 \mathrm{~km})$ and do not produce strong geoelectric fields (e.g. Simpson \& Bahr, 2005).

Lateral contrast in conductivity caused by complex geologic, topographic and bathymetric variations can contribute

*Corresponding author: ciar@bgs.ac.uk to strong geoelectric fields over large areas, which can be up to several tens of $\mathrm{V} / \mathrm{km}$ (Myllys et al., 2014; Love et al., 2018) posing a hazard to modern technology. With widespread adoption of low-resistance grounded infrastructure such as high voltage (HV) power networks induced geoelectric fields can equalize through the earthing points of these conductors. These quasi-steady DC currents are called geomagnetically induced currents (GICs) and, though small in comparison to the load carried, are a threat to the safe and optimal operation of $\mathrm{HV}$ transformers (Boteler, 2006; Pulkkinen et al., 2012). The most widely cited example of GIC damage is the collapse of a Québec-Hydro network in March 1989 (Bolduc, 2002; Boteler, 2019). Recent estimates of the cost of a similar widespread power outage suggest losses on the order of tens of billions of US dollars per day in advanced economies (e.g. Schulte in den Bäumen et al., 2014; Oughton et al., 2018).

Over the past two decades, a large effort has been directed towards understanding the risk posed to power networks across 
the world (Mac Manus et al., 2017; Rosenqvist \& Hall, 2019; Sokolova et al., 2019). GICs are a function of the induced geoelectric field coupled to the resistance and topology parameters of the affected power grid (e.g. Albertson et al., 1981). Modelling the response of a power grid to a uniform input geoelectric field is generally well-understood and many GIC analyses begin at this point (Horton et al., 2012; Caraballo et al., 2020). This simple field structure has often been adopted by industry within worst case scenarios and real-time analysis software (e.g. Fernberg, 2012; North-American Electric Reliability Corporation, 2016). However, research over the past decade has shown that this assumption is too simplistic and will cause a poor estimate of GIC during even modest storms (Beggan et al., 2013; Viljanen \& Pirjola, 2017; Blake et al., 2018; Love et al., 2018; Sun \& Balch, 2019). Hence, both the spatial and temporal pattern of the magnetic field and the underlying conductivity structure must be accounted for in order to produce realistic geoelectric field models over a wide region (Lucas et al., 2020).

Locally, natural variations in the geoelectric and magnetic field can be measured using three or more non-polarizable electrodes to record the voltage in an east-west and north-south direction in conjunction with a three-axis magnetometer. This is the basis of the magnetotelluric (MT) method (Cagniard, 1953; Wait, 1982) which derives a frequency-dependent stationary transfer function between the magnetic and electric fields, the impedance tensor, using the assumption that the inducing magnetic field is spatially uniform. Typically, MT sites are occupied from a few days to a couple of months allowing for a transfer function with periods between $0.01 \mathrm{~s}$ and around $100,000 \mathrm{~s}$ to be computed (Chave \& Jones, 2012). The impedance tensor can then be used to estimate the induced geoelectric field at any other time when only magnetic field recordings or models are available.

Longer term measurements of the geoelectric field are rarer and are only available at a few locations around the world including the UK, Japan (Fujii et al., 2015), Hungary (Kis et al., 2007) and the USA (Blum et al., 2017). The earliest known long-term measurements in the UK are from the Greenwich observatory in London where geoelectric field measurements were made between 1868 and 1895, before noise from the recently-introduced DC electric trains prevented the natural signal from being observed. The Greenwich system used four copper grounding plates separated by approximately $5 \mathrm{~km}$ with wiring running along the (pre-electrified) railway lines around London. The geoelectric field was measured by the deflection of an iron needle placed between two coils sited in the observation hut, subsequently recorded onto photographic paper. Plots of the original geoelectric field measurements are available in the observatory yearbooks, for example, but are usually un-scaled (though see Preece, 1882 who reported a current of 3.3 A).

The Japanese and Hungarian measurements have been ongoing for many decades, since the International Geophysical Year (1957) in the case of Hungary and even earlier for Kakioka Observatory (beginning in 1932). Measurement campaigns in the USA have been sporadic in the past century but continuous monitoring was restarted in 2016 at Boulder Observatory. Since 2012, the British Geological Survey (BGS) have collected geoelectric field measurements at their three UK observatories at a cadence of $10 \mathrm{~Hz}$, transmitting them in real-time to the data centre in Edinburgh. The three BGS observatories are located in the far north on the Shetland Islands (Lerwick), southern Scotland (Eskdalemuir) and southwest England (Hartland), shown in Figure 1a. With these exceptions, long-term real-time geoelectric field measurements are extremely limited across the globe.

The paucity of widespread measurements of the geoelectric field elsewhere means it must instead be modelled. Kelbert (2020) provides a review on the contemporary state-of-the-art in GIC and geoelectric field modelling. There are three main approaches for calculating the geoelectric field from measured magnetic field variations: (a) homogeneous fields from halfspace or 1D conductivity models (e.g. Boteler \& Pirjola, 1998), (b) 2D maps of the electric field at the surface created from models of bulk lithological properties, MT surveys or from airborne measurements in a thin-sheet or multi-sheet model (e.g. Thomson et al., 2005; Ivannikova et al., 2018) or (c) full 3D conductivity estimates of the electric field using finite element analysis derived from inversion of a large number of measurements or synthetic models (e.g. Pokhrel et al., 2018; Rosenqvist $\&$ Hall, 2019). These three approaches can be considered to represent the end-members in the trade-off between accuracy, speed of computation and spatial applicability. For example, approach (a) is fast and accurate to compute but is only representative at a single location, while approach (c) is accurate and can reproduce the geoelectric field across a large region but requires large resources to compute. At present, approach (b) offers a compromise between the three factors, offering lower accuracy but capturing a wide area with reasonably quick computation times.

As well as the above trade-offs, differing levels of effort are required to construct the models. In the case of approach (a), 1D models, often from magnetotelluric measurements must be made across a large region (or country) which can take many years to complete (Schultz et al., 2006-2018) and significant resources, though the advantage is that the model constantly improves with more data. Approach (c) requires significant effort to create a large-scale 3D model (e.g. Robertson et al., 2020), which may be made from information gathered from MT surveys and other sources, but may have larger uncertainties in regions without ground measurements. Finally, approach (b) is based on incomplete knowledge of lithological and deep crustal conductivity acquired from geological surveys but is feasible to construct from readily-available information (see Beamish, 2013, and references therein). While all these approaches offer plausible models of the geoelectric field (within a narrow period range) based on ground conductivity, validating them across a large region is more difficult.

Progress in recent years has focused on making better use of existing data. Marshall et al. (2019) examine some of the different methods of combining 1D or 3D conductivity models of approach (a), as do Kelbert et al. (2017). Over the past decade, We have used the thin-sheet approach to model the geoelectric response to increased geomagnetic activity due to space weather in the UK. The thin-sheet model is based on the approach by Vasseur \& Weidelt (1977) as modified by Beamish et al. (2002) and McKay (2003). The model consists of $10 \mathrm{~km}$ grid cells representing the conductance of the $2 \mathrm{D}$ surficial lithology (to a depth of $3 \mathrm{~km}$ ) with a series of 1D conductivity models at depth to represent the six geological terranes beneath the British Isles. The thin-sheet model code has been used to study the GIC risk in the UK (Beggan et al., 2013; 

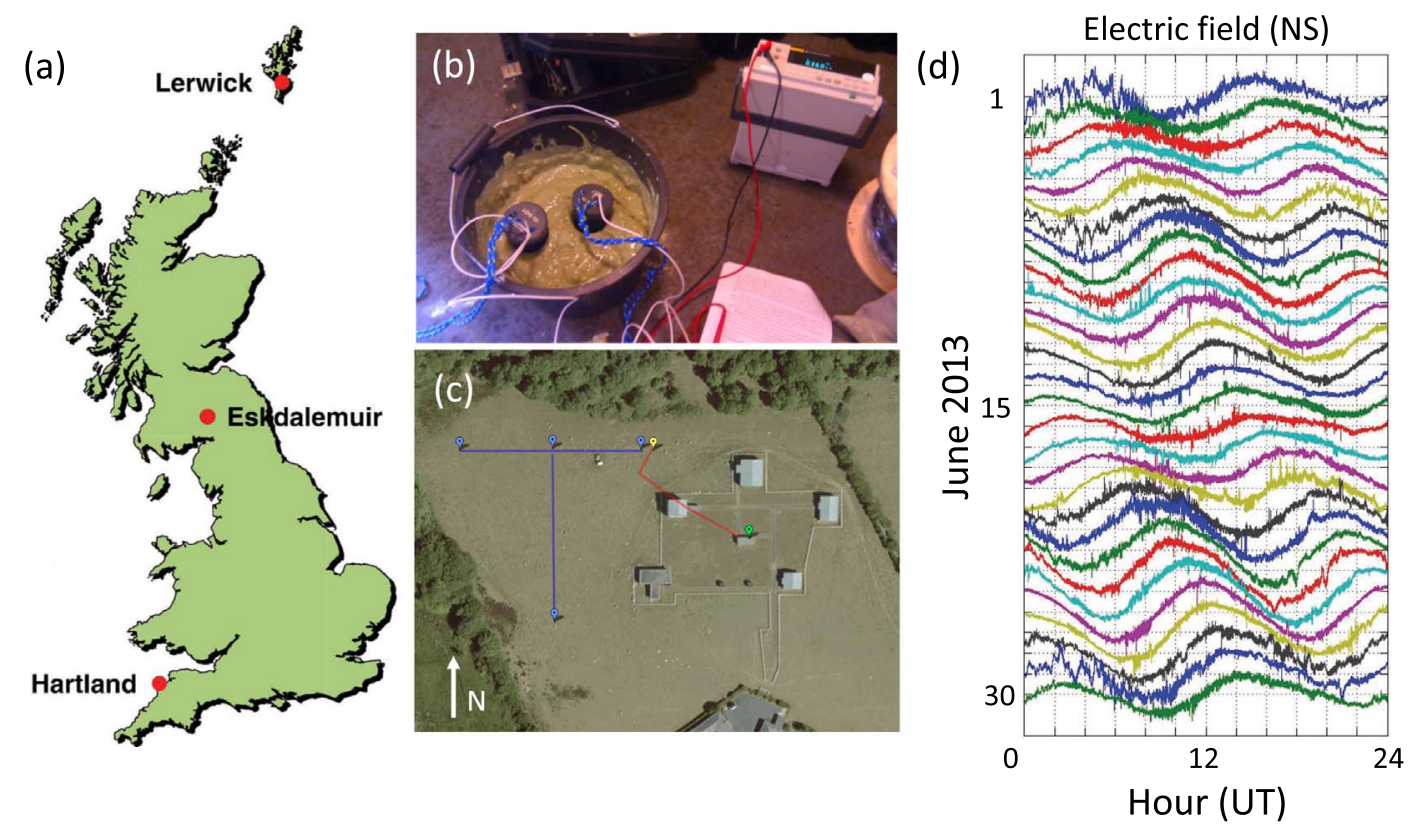

Fig. 1. (a) Location of the three UK geoelectric measurement systems. (b) LEMI 701 electrodes on test. (c) Map of geoelectric probe locations at Hartland observatory. (d) Stackplot of North-South (NS) component of the geoelectric field at Hartland for June 2013 showing a clear M2 (lunar) tidal periodic signal with peak to peak variation of around $20 \mathrm{mV} / \mathrm{km}$.

Beggan, 2015; Kelly et al., 2017), as well as in Austria (Bailey et al., 2018) and New Zealand (Divett et al., 2020). However thin-sheet models are known to have limitations and provide a general approximation of the true geoelectric field rather than a highly accurate model.

In the following sections, we focus on three main aspects of recent BGS work in geoelectric field research to provide an overview of our present capabilities. Firstly, we describe the three UK geoelectric observatories and give examples of their measurements (Sect. 2). We use the long-term geoelectric and magnetic field measurements to compute MT transfer functions for the observatories in Sections 3 and in Section 4, we describe the thin-sheet method in detail. In Section 5, we compare the geoelectric field computed by the MT transfer functions and output by the thin-sheet model with the independent measurements made at the observatories for a number of geomagnetic storms. Finally, we use both the MT impedance functions and the thin-sheet model to estimate the geoelectric field induced during the two largest storms of the digital era (March 1989 and October 2003) in Section 6. We discuss the results in Section 7 before making our conclusions.

\section{Measuring the geoelectric field}

For long-term measurements of the geoelectric field, the voltage between two points in the ground is measured using a pair of non-polarising electrodes to minimise self-potential that would otherwise appear as noise in the recording of differential voltage data (and therefore contaminate the signal of interest). At each UK observatory a similar (though not identical) set of sensors and recording equipment are used. The electrodes are of the LEMI-701 type, manufactured at the Lviv Centre of
Institute for Space Research, Ukraine (https://lemisensors.com/). These were chosen for their low noise and long-term stability. The LEMI-701 electrodes are set into a copper and coppersulphate solution $\left(\mathrm{Cu}-\mathrm{CuSO}_{4}\right)$, as shown in Figure $1 \mathrm{~b}$. At the observatories, two pairs of electrodes are installed in small hand-dug pits at least $0.5 \mathrm{~m}$ deep and set in a clay-CuSO${ }_{4}$ mix aligned in geographical North-South and East-West directions, with a dipole length of between 66 and $100 \mathrm{~m}$.

At the northernmost observatory, Lerwick, the observatory lies around $4 \mathrm{~km}$ southwest of a small town on a short peninsula surrounded by the sea. The terrain is generally wet, on a slight incline to the south, and is bounded by a small freshwater lake at the southern edge. The North-South probes are separated by $99 \mathrm{~m}$ and the East-West probes are $91 \mathrm{~m}$ apart. Through an analogue to digital converter (ADC) with bespoke pre-amplifiers, a Guralp data logger collects and stores the data before it is sent in real-time across the internet to the BGS office in Edinburgh. The Lerwick system was installed in early 2012.

The Eskdalemuir observatory occupies a quiet rural valley in the southern part of Scotland approximately $35 \mathrm{~km}$ from the west coast and $70 \mathrm{~km}$ from the east coast. The geoelectric field probes are installed around $400 \mathrm{~m}$ from the nearest building in a wet boggy field. The North-South probes are separated by $66 \mathrm{~m}$ and the East-West probes are $86 \mathrm{~m}$ apart. As with Lerwick, a junction box containing a pre-amplifier and ADC sends the data to a logging system in a nearby underground vault where the data are passed to the central office and stored permanently. The Eskdalemuir system began recording in mid2013.

Hartland observatory lies in the southwest corner of England close to the Bristol Channel. The site is a few hundred metres north of Hartland village on flat, relatively dry and welldrained land. The North-South probes are separated by $69 \mathrm{~m}$ and the East-West probes are $76 \mathrm{~m}$ apart, shown as blue lines 
in Figure 1c. A similar data collection system to the other observatories exists. The geoelectric field system in Hartland was installed in early 2013.

Data from all three observatories are posted to the BGS website every $10 \mathrm{~min}$ and plots showing the past $6 \mathrm{~h}$, the day to date and the past 30 days are available for browsing. Figure 1d shows a stackplot of the north-south component from Hartland for June 2013. There is a clear lunar tidal signal visible (approximately $20 \mathrm{mV} / \mathrm{km}$ peak to peak) with a period of $12.42 \mathrm{~h}$. Note that some minor space weather activity is visible at the beginning of Days 1 and 29.

The geoelectric field systems were installed to test whether good quality data could be collected at the existing geomagnetic observatories. Due to the generally challenging environments in the remote locations and the normal decay of the probes, maintaining continuous high-quality measurements has not been possible. Various redesigns of the systems over the years as well as damage from lightning or component failure have caused gaps or poor quality data for analysing longer periods. This is in addition to drifts caused by the degradation of the probes and occasional steps in the data. However, a considerable effort has been made to clean up the dataset where feasible and new instrumentation is planned.

In addition to the range of geomagnetic latitudes, the three observatories lie in very different settings in terms of proximity to the coast, altitude and underlying geology. This gives rise to strong variations in the electric and magnetic environment experienced during space weather events. Due to the relatively quiescent nature of space weather in the approximately eight years of operation to date, the geoelectric field measurements encompass relatively few intense events e.g. the 17 March 2015 and the 7-8 September 2017 storms are two of the larger storms of solar cycle 24 .

Figures 2 and 3 show the minute-mean values of the magnetic and geoelectric fields recorded at the three observatories for these dates. The upper panels $(\mathrm{a}-\mathrm{c})$ shows the horizontal strength of the magnetic field variation $\left(H=\sqrt{X^{2}+Y^{2}}\right)$ relative to its quiet time background (in $\mathrm{nT}$ ) with the variation of the two geoelectric horizontal field components (in $\mathrm{mV} / \mathrm{km}$ ). Note the curves have been offset from each other to show the detail. It can be observed at each site that it is the high frequency variations of the magnetic field that induce the geoelectric field with the long period variations being largely damped. Only Hartland has long-period variations due to the tidally-induced field from high range and rapid flow of seawater in the Bristol Channel.

The bottom panel (d) in both figures shows the measured GIC from a Hall probe installed at Torness $400 \mathrm{kV}$ substation in central Scotland, around $90 \mathrm{~km}$ northeast of Eskdalemuir (McKay, 2003). The GIC response of the high voltage power grid can be considered to be a band-pass filtered version of the geoelectric field. Again, it is clear that the short-period variations of the geoelectric field have the strongest influence on measured GIC.

Finally, a storm on the 26 August 2018 is shown in Figure 4. Though a relatively minor storm (G3 on the NOAA geomagnetic storm scale), it coincided with the deployment of the differential magnetometer method (DMM) systems of Hübert et al. (2020) which allowed a comparison of both line and substation GIC to be made. Unfortunately, only a single channel of electric field data at each observatory was in operation due to
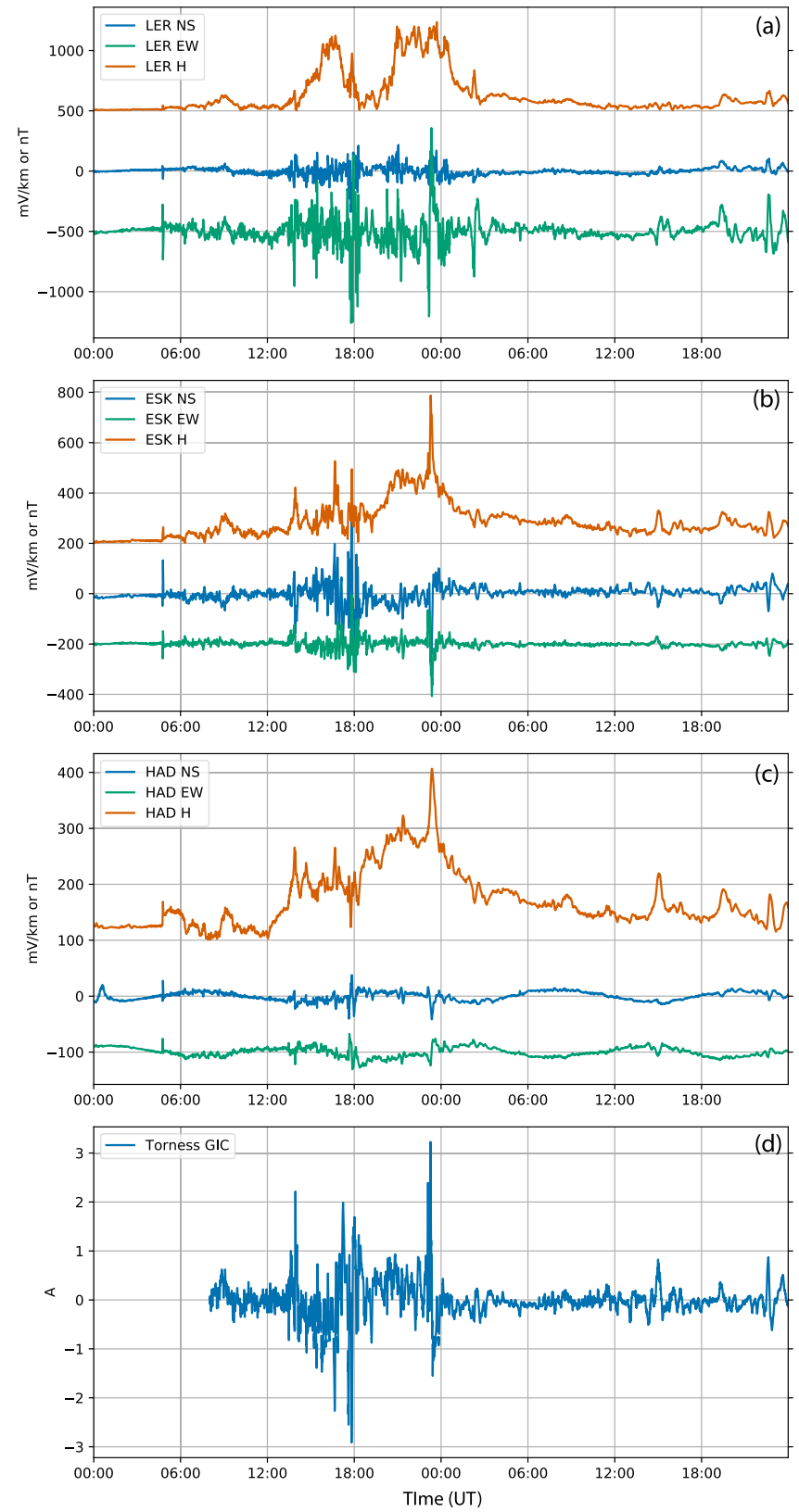

Fig. 2. Measurements of the geoelectric field components (NorthSouth \& East-West), the variation of the horizontal component $(H)$ of the magnetic field and GIC (in amps) for 17-18 March 2015 at: (a) Lerwick; (b) Eskdalemuir; (c) Hartland; (d) GIC at Torness substation, East Scotland. Note the magnetic and geoelectric curves are offset from zero.

various technical issues. Note the variation of the magnetic and geoelectric fields are smaller than the 2015 and 2017 storms as were the resultant GICs.

\section{Magnetotelluric impedance functions}

Using the geoelectric (E) and simultaneous magnetic field (B) measurements at the three observatories we computed the 

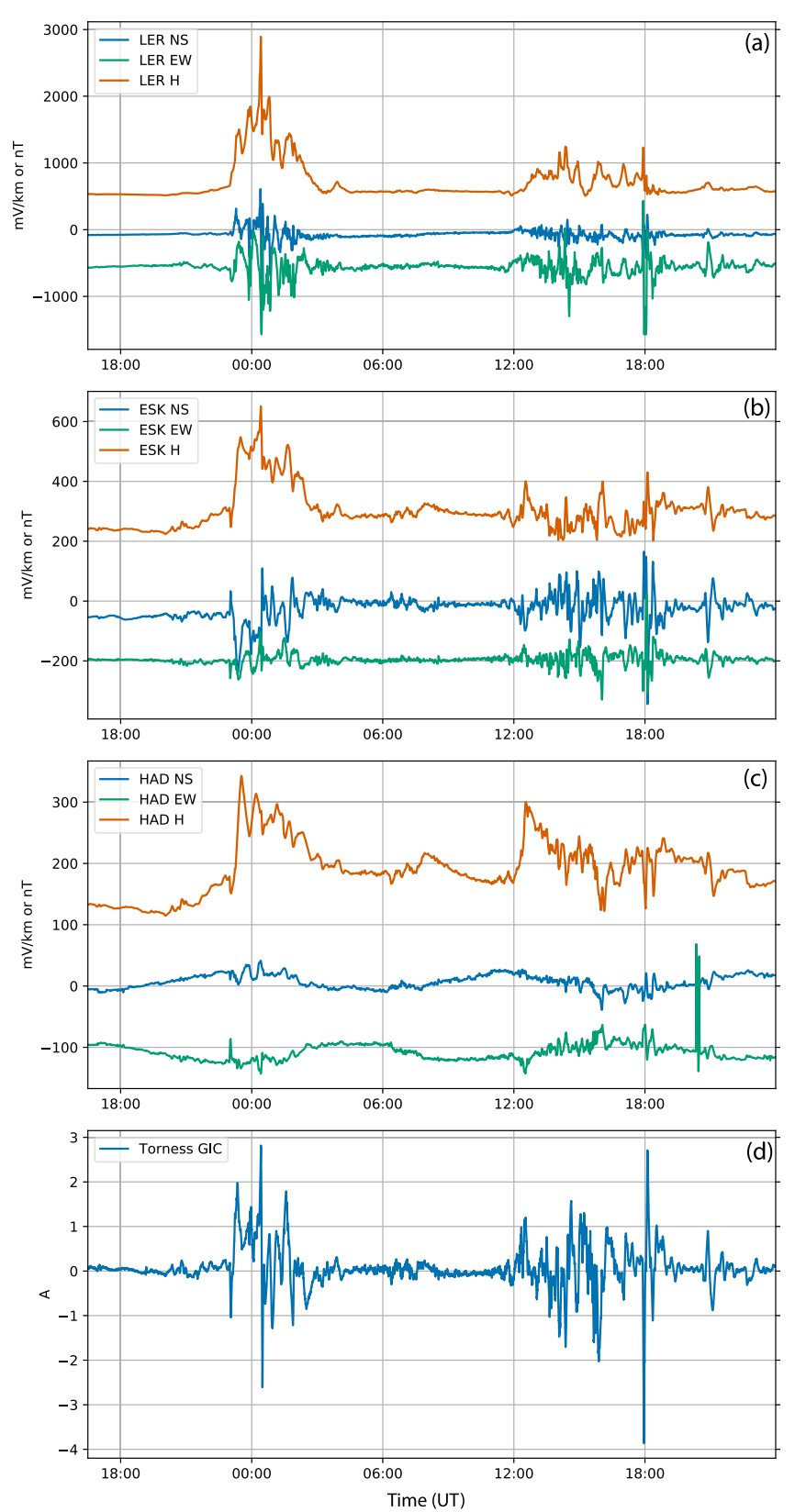

Fig. 3. Measurements of the geoelectric field components (NorthSouth \& East-West), the variation of the horizontal component $(H)$ of the magnetic field and GIC (in amps) for 7-8 September 2017. (a) Lerwick; (b) Eskdalemuir; (c) Hartland; (d) GIC at Torness substation, East Scotland. Note the magnetic and geoelectric curves are offset from zero.

magnetotelluric impedance tensor $\mathbf{Z}$ at each site (e.g. Wait, 1982). It is defined in the frequency domain as:

$$
\mathbf{E}(\omega)=\frac{1}{\mu_{0}} \mathbf{Z}(\omega) \cdot \mathbf{B}(\omega)
$$

with $\mu_{0}$ the magnetic permeability and the angular frequency $\omega$. We chose six months during 2015 of uninterrupted and relatively noise-free time-series from each observatory to derive the impedance in the frequency range of $20-30,000 \mathrm{~s}$ using
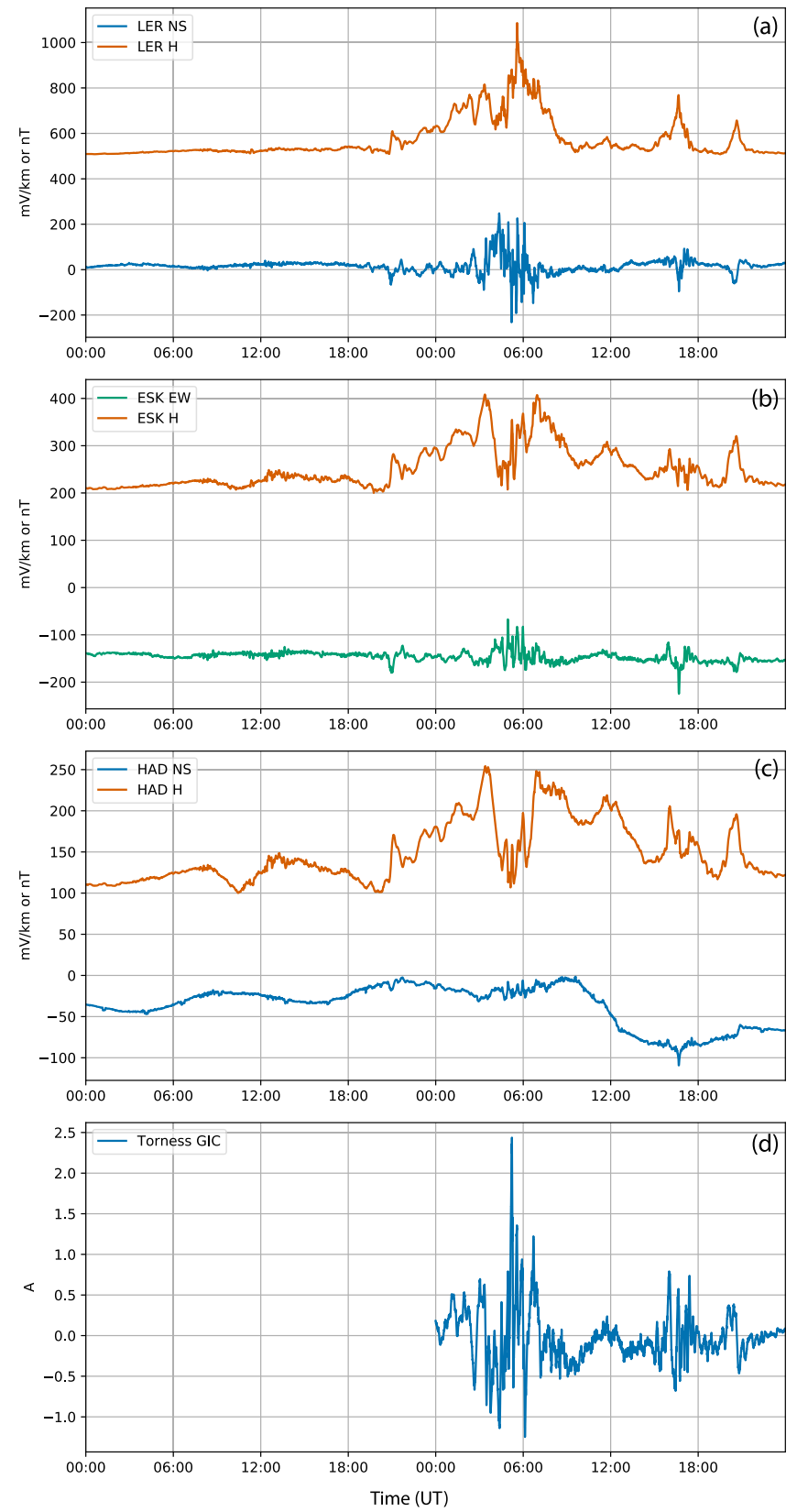

Fig. 4. Measurements of the geoelectric field component (NorthSouth or East-West), the variation of the horizontal component $(H)$ of the magnetic field and GIC (in amps) for 25-26 August 2018. Only one electric channel at each site was available. (a) Lerwick; (b) Eskdalemuir; (c) Hartland; (d) GIC from Torness substation, East Scotland. Note the magnetic and geoelectric curves are offset from zero.

the robust statistical algorithm of Smirnov (2008). $\mathbf{Z}$ is assumed to be temporarily stationary - it represents the underlying electrical conductivity distribution which can be assumed to be constant in the case of the UK. We tested this and derived $\mathbf{Z}$ from different time periods of recordings at the three observatories with almost identical outcomes (within the uncertainties). 

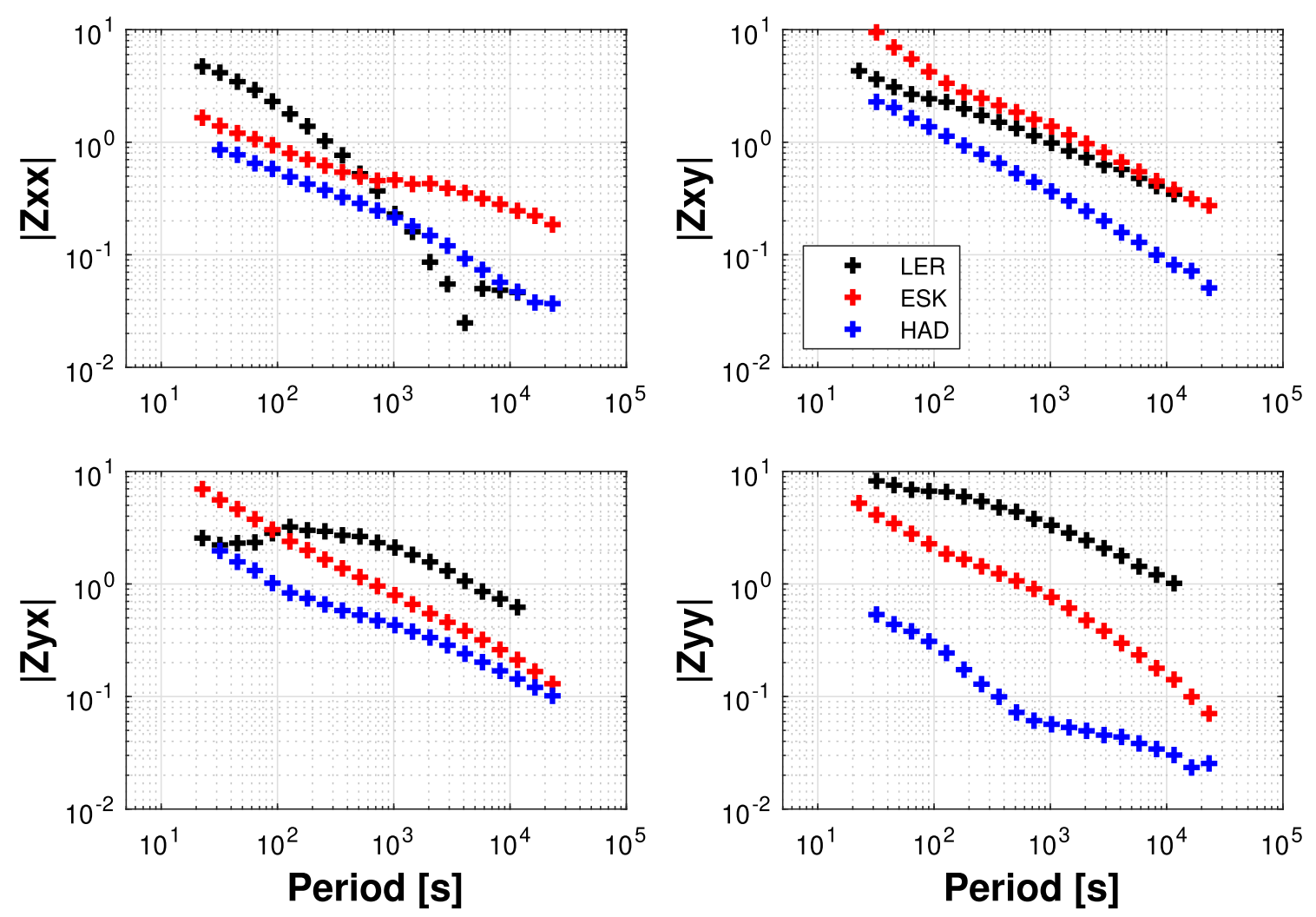

Fig. 5. Components of the two-dimensional MT impedance tensor $\mathbf{Z}$ at all three UK observatories. Differences in curves reflect the varying underlying electrical resistivity structure across Britain.

Figure 5 shows the components of the impedance for periods of $20-30,000 \mathrm{~s}$ for each of the three observatories. The transfer functions show the largest response at short periods (20-1000 s) with an approximately exponential decrease (i.e. a linear change in logarithmic scale) with longer periods beyond $1000 \mathrm{~s}$. This is consistent with the observations of the geomagnetic to geoelectric response in Figures 2-4. In general, Hartland has the weakest magnitude response to magnetic field variations, while Lerwick and Eskdalemuir have a stronger response. The differences in the structure of the curves for each component relate primarily to the geology beneath each site, though at longer periods the associated errors become larger too (not shown).

From our observations, during storm times, the geoelectric field estimates from the MT transfer functions tend to underestimate the magnitude of the measured geoelectric field. This can be attributed to a number of causes, as discussed for example in Campanya et al. (2019). Some signal loss can be explained by the limited frequency content (the magnetic field data is sampled at $1 \mathrm{~min}$ and the impedance tensor is only derived for 10-30,000 s). Additionally, the plane wave approximation, fundamental for the MT tensor relationship, may not be able to explain all of the signal during geomagnetic storm times (Viljanen et al., 1999; Romano et al., 2014; Simpson \& Bahr, 2020). For example, Simpson \& Bahr (2021) demonstrate they require frequency-based correction factors to force their MT transfer functions computed from quiet-time data to match storm-time geoelectric field measurements.
In the case of dense MT surveys, like in the USA (Schultz et al., 2006-2018), the interpolation of impedances over the whole modelling domain becomes feasible and the estimation of the geoelectric field over larger areas is possible (Bonner \& Schultz, 2017). This is desirable for the accurate modelling of GICs which requires the integration of electric fields along the affected ground infrastructure like power lines or pipelines which can extend over long distances crossing several regions of lateral conductivity variation. We will use the MT transfer functions to estimate geoelectric fields from historic large storm events (see Sect. 5).

\section{Thin-sheet modeling of the geoelectric field}

To model the regional geoelectric field, we wish to combine the response of the ground conductivity in a region with the spatial and temporal measurements of the rate of change of the horizontal components of the magnetic field. We use a thin-sheet model to do this which has the advantage that spatially variable magnetic fields can be used as an input. The modelling code is based upon the work of Vasseur \& Weidelt (1977) which has been employed in previous studies noted in the Introduction. The code computes the surface electric field arising at a particular period (for example, $120 \mathrm{~s}$ or $2 \mathrm{~min}$ ) from a 2-D conductivity model of the surface and a layered subsurface. Using a series of Green's functions convolved with a two-dimensional thin-sheet representation of the conductance, 

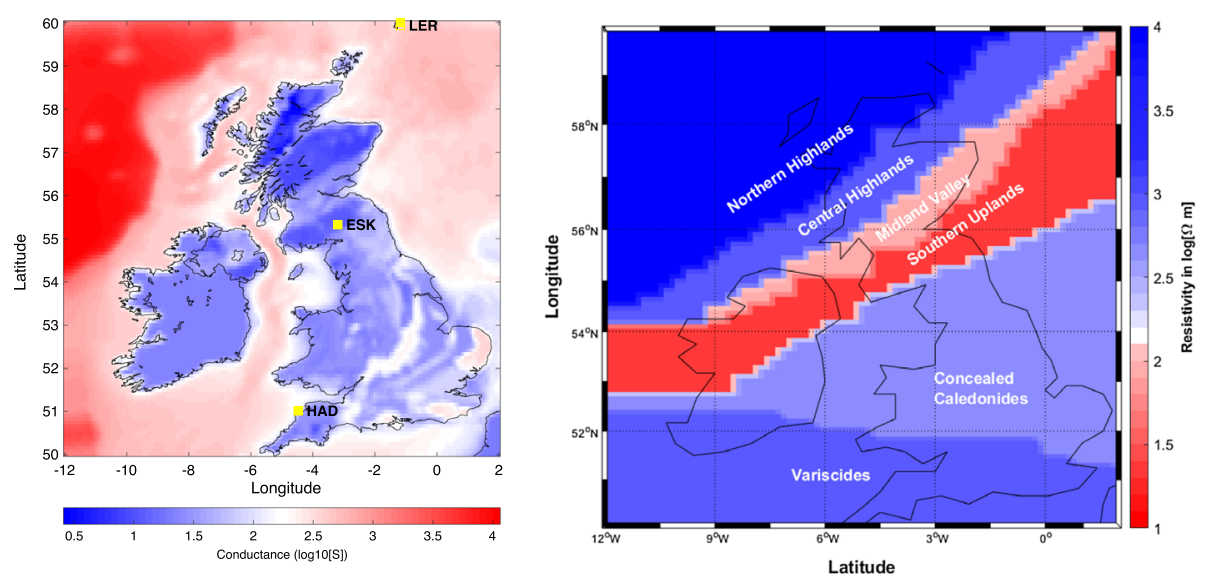

Fig. 6. Left panel: Thin-sheet conductance model of the UK and surrounding seas with a cell size of $10 \mathrm{~km}$ (units of log 10 (Siemens)). Right panel: Block model underlying the thin-sheet conductance model with electrical resistivities assigned according to geologic domains after Beamish \& White (2012).

the effect that conductivity variations have on redistributing regional or "normal" currents induced elsewhere (for example, in the sea) can be computed. The surface layer can be regarded as an infinite thin-sheet of finite laterally-variable conductance, across which certain boundary conditions apply.

For the top layer, we use conductance values in a $10 \mathrm{~km}$ grid-cell model of the UK developed by Beamish \& White (2012) and Beamish (2013). The lithology-based classification of bedrock is used to provide an association with the petrophysical rock parameters controlling bulk conductivity, assumed to represent the conductance to a depth of $3 \mathrm{~km}$. The $10 \mathrm{~km}$ map is based on a reduced version of a 1:625 k scale (approximately $1 \mathrm{~km}$ ) map, and is comprised of 86 lithological classifications. Offshore, seawater is assumed to have a conductivity of $3 \mathrm{~S} / \mathrm{m}$ and the model accounts for changes in bathymetry. The model extends $1200 \times 1680 \mathrm{~km}(121 \times 169$ cells $)$ and, in order to reduce edge effects, an additional 5 cells of padding are added to each edge to make the final grid of $131 \times 179$ cells. The padding cells have values close to of the average conductance of the entire model. Figure 6 (left panel) shows the 2D thin-sheet conductance map of the UK.

Below $3 \mathrm{~km}$, a series of 1D models, each with 20 layers, are used to represent the underlying structure of the British Isles to a depth of approximately $1000 \mathrm{~km}$. The shallow to mid-crustal tectonic setup of the the UK can be described by six major geologic terranes. We use the conductivities from the terrane model of Beamish et al. (2002), categorised as the more resistive Northern and Central Highlands and the less resistive Midland Valley and Southern Uplands of Scotland. South of the Iapetus Suture Zone covering much of England lies the Concealed Caledonides terrane with a conductive mid-crustal anomaly (Banks et al., 1983). The southern part of the UK is considered as part of the Variscan Zone. Ádám et al. (2012) provide values for the 1D conductivity models of these terranes. Figure 6 (right panel) shows the resistivity of the models at a depth of $6.5 \mathrm{~km}$. The influence of these underlying 1D models on the magnitude of the induced geoelectric field at the surface was examined in detail in Beggan (2015). We acknowledge that this lithospheric model is entirely synthetic and can in reality differ from the true three dimensional electrical conductivity distribution in the crust and upper mantle. In the absence of countrywide MT data, it is nevertheless a good first approximation using available data and geological information.

The code requires the average rate-of-change of the horizontal magnetic field for a fixed period as an input. Different strategies can be chosen to incorporate the magnetic field variation over the area of interest. In previous papers (e.g. Kelly et al., 2017), we have used the $\Delta B$ value of the external field recorded every minute at several observatories by assuming the amplitude of the horizontal field changes sinusoidally with a period of length $T$ (in minutes), as an electrojet current system moves back and forwards in latitude, the input field strength $\left(H_{0}\right)$ at any time $(t)$ can be represented by $\mathbf{B}_{H}=H_{0} \sin (2 \pi t / T)$. However, this does not impose any bandpass filtering on the input magnetic field and implies a fixed frequency on the output geoelectric field.

Instead, for this study, we adopted an alternative method suggested in Bailey et al. $(2017,2018)$ which uses the rate of change of the horizontal components of the field $\left(\mathrm{d} B_{X} / \mathrm{d} t\right.$ and $\mathrm{d} B_{Y} / \mathrm{d} t$ ). Their Austrian-based study used the difference in the magnetic values every $5 \min (\Delta t=300 \mathrm{~s})$ and, in combination with a model of the country's high voltage power network, successfully matched the GIC measurements at several sites in the country. We replicate this approach but using a difference of $2 \min (\Delta t=120 \mathrm{~s})$ which matches the available magnetic time-series of minute-mean values. We also refer to Ivannikova et al. (2018) who showed that their thin-sheet geoelectric field matched that computed with a full 3D model to within $8 \%$ for periods longer than $50 \mathrm{~s}$.

To implement this approach, maps of the magnetic field across the region are created for each minute of the day using spherical elementary current systems (SECS) to interpolate between measurement sites (Amm, 1997). The SECS method produces good estimates of the magnetic field across the modelling domain when there are typically greater than five observatories available in a closely spaced $(<500 \mathrm{~km})$ configuration. If there are more observatories available, the resulting interpolation improves (McLay \& Beggan, 2010). 
The difference of the magnetic field every $2 \mathrm{~min}$ is computed (giving 720 snapshots per day) and each snapshot of the magnetic field is passed into the thin-sheet code. The output consists of geoelectric maps for every 2 nd min of the day. Note, we also tested $\Delta t$ of 5 and $10 \mathrm{~min}$ (300 and $600 \mathrm{~s}$ ) and found similar patterns of variation, though with smaller amplitude ranges. In practice, we run the thin-sheet model for each of the $1 \mathrm{D}$ terrane models and combine the results by extracting the corresponding part of each terrane on land into the final model. This is, in effect, a blocky pseudo-3D approximation, similar to Myllys et al. (2014) or Viljanen \& Pirjola (2017).

We can then test how well the thin-sheet geoelectric field values compare to the recorded measurements at the three observatories. However, there are a number of limitations, which include the extent of the thin-sheet model and the effect of regional or local geological features. In the first case, the thinsheet model does not extend to the Lerwick Observatory, though it is quite close to the edge (around $20 \mathrm{~km}$ ). To extract the geoelectric field at this site, we must extrapolate the thinsheet model slightly, which introduces some additional uncertainty. At Eskdalemuir, it is well known that there is a shallow local crustal anomaly though this mostly affects the vertical magnetic component (Banks et al., 1996). Finally, Hartland is strongly influenced by a tidal geoelectric signal which is not captured by the thin-sheet model due to the band-pass filter applied to produce the $\mathrm{d} B / \mathrm{d} t$ values; however, we are interested primarily in the space weather effects which are demonstratively shorter-period (see Figs. 2-4).

\section{Comparison between electric field models and measurements}

We examine the geoelectric field modelled for three of the larger storms experienced in the UK between 2013 and 2018: 17-18 March 2015, 7-8 September 2017 and 26 August 2018. We compare the MT-derived and the thin-sheet model geoelectric field values against the measured data at the three UK observatories.

We isolate the external field part of the magnetic field by removing the average quiet-time mean value of magnetic component computed from measurements made a few hours prior to the storm's initiation. For example, local night-time values between 02:00 and 03:00 LT a day or so prior to a storm are often the quietest. The external field will comprise ionospheric and magnetospheric sources as well as the magnetic effect of telluric currents which may be a relatively large contribution (Juusola et al., 2020).

To compute the external magnetic field variation over the North Sea we used SECS with data from the three BGS observatories complemented with other observatory or variometer data from Ireland, the Faroe Islands, France, Germany, Belgium, Denmark and Norway in order to expand the region over which the external magnetic field can be computed. Figure 7 shows the spatial extent of the magnetic measurements available. Note not all stations are available for each storm (see Table 1). In general, we find using a larger number of magnetic observatories creates a better model of the magnetic field over the region, which in turn produces a better match between the

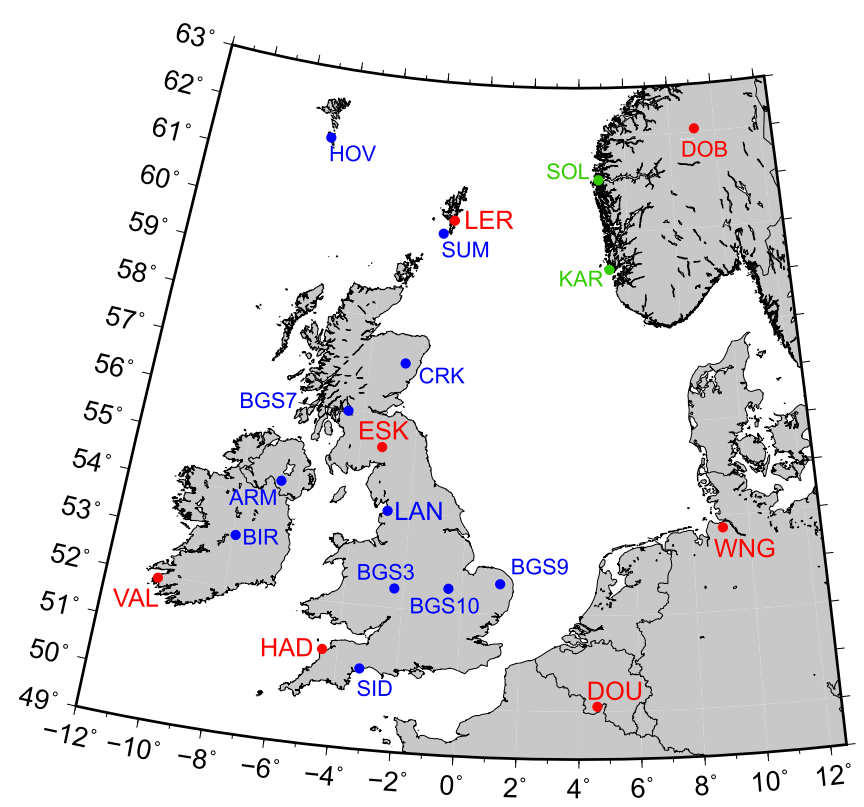

Fig. 7. Location of the INTERMAGNET-standard observatories (red), calibrated variometers (green) and variometers (blue) used for SECS magnetic field interpolation.

measured and modelled geoelectric field. For the thin-sheet code this is related to a convolution and integration of the magnetic field with the conductivity model over the entire grid.

\subsection{March 2015 storm}

The first so-called "super" storm of solar cycle 24 was the St. Patrick's Day storm, starting on the 17 March 2015 with the |Dst| index exceeding $200 \mathrm{nT}$ (Wu et al., 2016). The storm followed a partial-halo Coronal Mass Ejection (CME), associated with an X-ray solar flare of moderate intensity (C9.1), that occurred on the surface of the Sun on 15 March 2015. The most rapid geomagnetic variations were associated with periods of strongly negative IMF $B_{z}$ of $-20 \mathrm{nT}$. In the UK, the storm exhibited two main bursts of activity on the evening of the 17 March separated by around 6 h (see Fig. 2).

For the March 2015 storm, magnetic data from eight observatories were available, allowing interpolation of the magnetic field variation across the UK. The northernmost variometers are Dombås (DOB) and Karmøy (KAR) in Norway, with Dourbes (DOU) in Belgium being the southernmost observatory. Wingst (WNG) is the east-most observatory and Valentia (VAL) is west-most. While not ideal for SECS interpolation, as there is no control in the northwestern region, the spatial distribution covers the majority of the thin-sheet modelling area.

The thin-sheet model was run using the north $(X)$ component and east $(Y)$ components of the external magnetic field variation for a response period of $120 \mathrm{~s}$. In order to compare to the modelled field, the measured geoelectric field data were bandpassed between 120 and $3600 \mathrm{~s}$ using a Butterworth 3-pole filter. As the geoelectric field data are recorded at $10 \mathrm{~Hz}$, this removes much of the very short-period and some of the long period energy though as we noted in the previous section longer period variations do not have much influence on GIC. 
Table 1. Stations with magnetic data available for SECS interpolation.

\begin{tabular}{ll}
\hline Storm & \multicolumn{1}{c}{ Stations } \\
\hline Mar 2015 & DOB, DOU, ESK, HAD, KAR, LER, VAL, WNG \\
Sep 2017 & ARM, BIR, BGS3, BGS7, BGS9, BGS10, CRK, DOB, DOU, ESK \\
Aug 2018 & HAD, HOV, KAR, LAN, LER, SID, SOL, SUM, VAL, WNG \\
Mar 1989 & BGS10, CRK, DOU, ESK, HAD, HOV, LER, SOL, VAL, WNG \\
Oct 2003 & CRK, ESK, HAD, LER, VAL, WNG \\
\hline
\end{tabular}

Figure 8 shows the comparison of the geoelectric field measurements made at each observatory for the March 2015 storm. The measured data in blue, the MT-derived values are in green and the thin-sheet modelled values are in red. In Lerwick the geoelectric field variation reached over $1 \mathrm{~V} / \mathrm{km}$ peak-to-peak around 18:00 UT in the east component, while it was around $50 \%$ smaller at Eskdalemuir with a peak-to-peak change of $500 \mathrm{mV} / \mathrm{km}$. At the most southerly observatory, Hartland, the geoelectric field in this frequency band reaches around $50 \mathrm{mv} / \mathrm{km}$ peak-to-peak.

For the east component of the thin-sheet electric field at Lerwick the magnitude is not well captured, though the match is better in the north component. The MT values are closer, though do not match the peak values at all times. At Eskdalemuir, the thin-sheet comparison in phase and amplitude is much better in the north component compared to the east component, while in Hartland the magnitude is similar though the correlation is poorer (see Sect. 5.4 for further detail). As the east-west geoelectric field component of the thin-sheet model is poorest at the two northerly sites, it suggests a problem with modelling the variation of the magnetic field in these areas due to the limited spatial extent of ground stations used.

\subsection{September 2017 storm}

On 7 September 2017 one of the largest storms of the 24th solar cycle hit the Earth (Dimmock et al., 2019). A CME left the Sun at midday on 6 September and reached Earth's magnetosphere around $36 \mathrm{~h}$ later. Starting about 23:30 UT on 7 September, the first and deepest part of the storm lasted for around $3 \mathrm{~h}$, reaching a Dst of $-124 \mathrm{nT}$. At 13:00 UT on 8 September a second substorm was triggered, though not as large as the first part of the storm (Fig. 3).

To get a regional picture of the storm, data were collected from a network of Raspberry $\mathrm{Pi}$ magnetometers (denoted BGS3/7/9/10) (Beggan \& Marple, 2018), as well as a number of other variometers and observatories around the UK, Ireland, Belgium, Germany and Norway including the observatories (from INTERMAGNET), the Lancaster University AuroraWatch network of variometers (Case et al., 2017), a network in Ireland run by Trinity College Dublin (MagIE) (Blake et al., 2016) and data from the Troms $\varnothing$ Geophysical Observatory (TGO) network. The SOL and KAR sites host calibrated variometers which provide the variation of the field in addition the absolute values of the geomagnetic field vector, though the data are not as well controlled as at full observatories (where weekly baseline measurements are conducted). We also received data from the DTU-operated Faroe Islands Hov variometer, which helped to constrain the field variations in the northwestern area of the model. In total, magnetic data from twenty sites were collected, giving an excellent representation of the magnetic field variation across Britain and Ireland. As before, data were processed to remove the quiet time mean value of the horizontal components at each site, using the value for 02:00-03:00 local time from 7 September. Where the orientation of the sensor is unknown (as with the Raspberry Pi magnetometers) we rotated the quiet time horizontal components to match the estimated values of $X$ and $Y$ from a global magnetic field model, the 12th generation of the International Geomagnetic Reference Field (Thébault et al., 2015). The thin-sheet model was run for the storm using two days' worth of magnetic values for both the $X$ and the $Y$ magnetic field components.

Figure 9 shows the resulting band-pass filtered thin-sheet model output compared to the band-passed measurements of the geoelectric field from each observatory. The intensity of the September storm is comparable to, if not larger than, the March 2015 storm in terms of the peak-to-peak variations at each observatory. The plots show the two large substorms around midnight of the 7th September and 12:00-18:00 on the 8th. The electric field variation is over $1 \mathrm{~V} / \mathrm{km}$ in Lerwick, $500 \mathrm{mV} / \mathrm{km}$ in Eskdalemuir and $80 \mathrm{mV} / \mathrm{km}$ in Hartland. Note that the large values in Hartland around 21:00 on the 8th are an artefact.

For this storm, the thin-sheet model has performed better in capturing the magnitude and phase of the geoelectric field at all three sites. The MT values provide a good estimate of the geoelectric field too, matching best at Eskdalemuir and Hartland. We provide a more comprehensive quantitative evaluation of the data fit see Section 5.4.

\subsection{August 2018 storm}

Although the August 2018 storm was a relatively small event in the solar cycle, it was the largest storm of the year with a peak Kp of 7+. The total interplanetary magnetic field reached a strength of $21 \mathrm{nT}$ with a prolonged period of southward $B_{z}$ and the Dst index had a peak of $-174 \mathrm{nT}$. The storm was likely caused by a CME though no classic shock signature was observed. The storm coincided with the deployment of differential magnetometer method (DMM) system which allowed a detailed analysis of GICs in the $400 \mathrm{kV}$ high voltage power grid in East Scotland (Hübert et al., 2020).

For the magnetic field interpolation, fewer variometers were available for this storm (only 10 stations, e.g. due to maintenance issues), so the SECS model of the field is not as accurate as for the September 2017 storm. Magnetic data are available from Hov in the Faroe Islands in the north to Dourbes in Belgium to the south and we include some of the AuroraWatch 

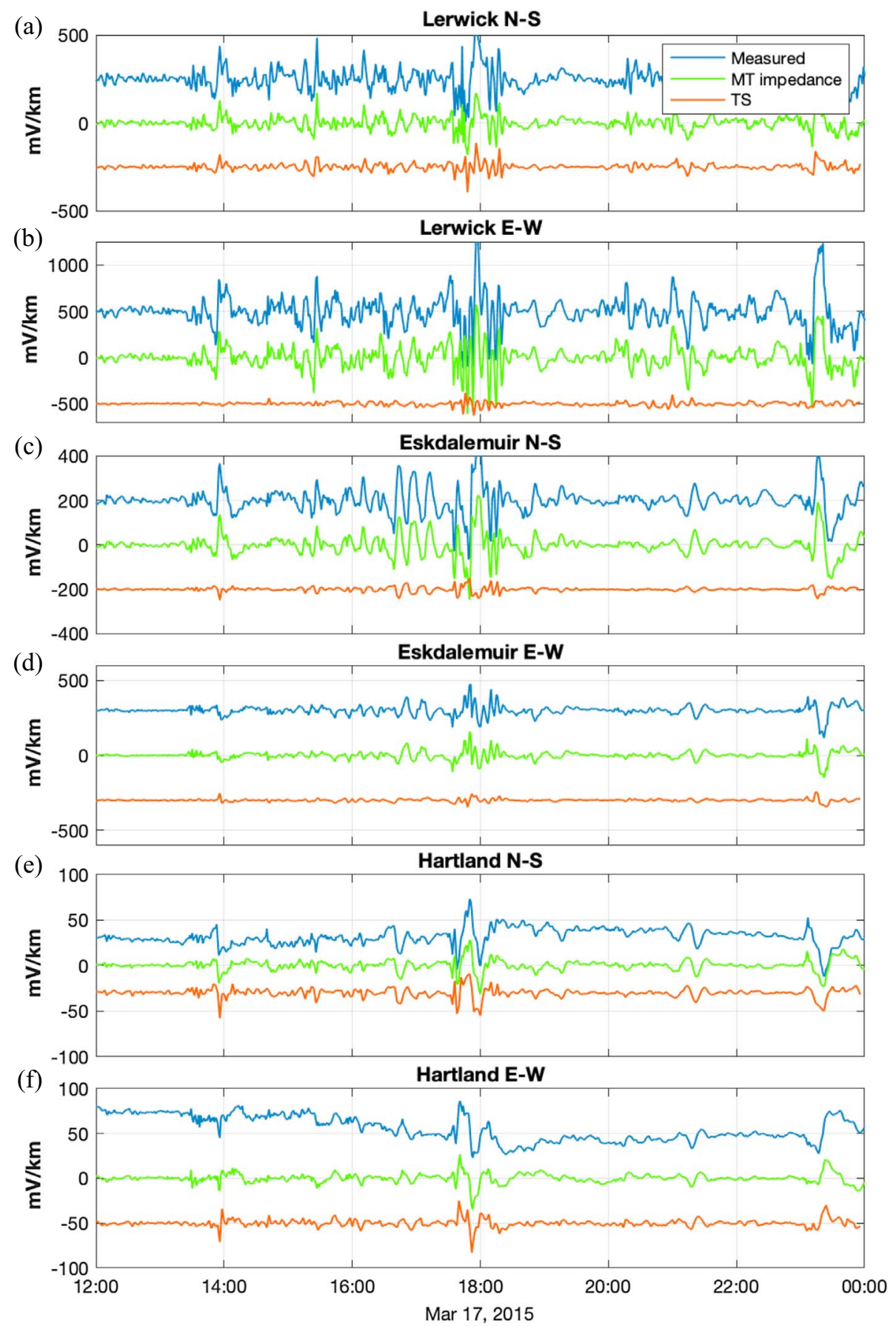

Fig. 8. Comparison of the thin-sheet (TS), magnetotelluric (MT impedance) and measured geoelectric field at (a, b) Lerwick, (c, d) Eskdalemuir and (e, f) Hartland observatories for 17 March 2015.

and BGS school magnetometer data. In addition, as noted in Section 2, the geoelectric field probes at LER, ESK and HAD only have data from one channel available at each site, due to a mixture of equipment failure and probe degradation.

Figure 10 shows the measured, MT-derived and thin-sheet modelled geoelectric field values. The overall magnitude of the field is much smaller than during the other two storms examined. Lerwick has a peak-to-peak variation of around $250 \mathrm{mV} / \mathrm{km}$ in the north component, while Eskdalemuir reaches around $100 \mathrm{mV} / \mathrm{km}$ in the east component. The geoelectric field in Hartland is very small, barely exceeding $20 \mathrm{mV} / \mathrm{km}$ peak-topeak. Similar to March 2015, the north component of Lerwick is poorly captured by the thin-sheet model in the main phase. The E-W geoelectric field component at Eskdalemuir is better 

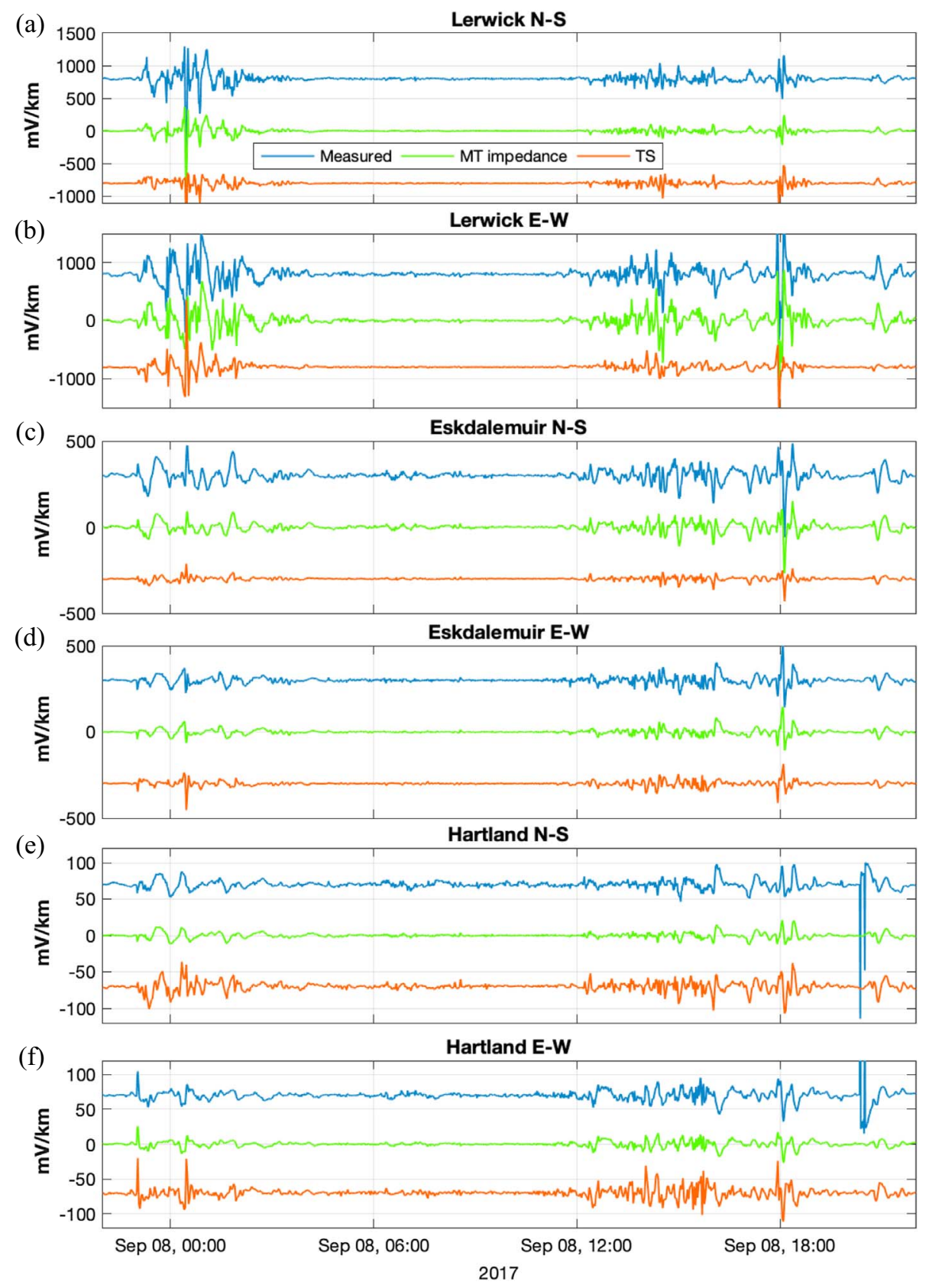

Fig. 9. Comparison of the thin-sheet (TS), magnetotelluric (MT impedance) and measured geoelectric field at (a, b) Lerwick, (c, d) Eskdalemuir and (e, f) Hartland observatories for 7-8 September 2017.

modelled, though not as well as the September 2017 storm, while Hartland has very small geoelectric field values and so the comparison is difficult to judge.

\subsection{Metrics to assess data fit between measured and modelled electric field data}

When comparing relatively "noisy" data sets such as the geoelectric field values, it is difficult to provide an over-arching metric that best describes the match between the model and measurements as minor fluctuations in the local geoelectric field cannot be captured by the regional model. This means that direct correlations between the time-series can be low despite appearing close.

To account for this we use a selection of metrics to assess quantitatively how well the models match the measurements. As well as the standard correlation between the time-series, following Torta et al. (2014), we compute the $P$-metric for each storm using,

$$
P=1-\frac{\mathrm{RMSD}_{\mathrm{om}}}{\sigma_{o}}
$$



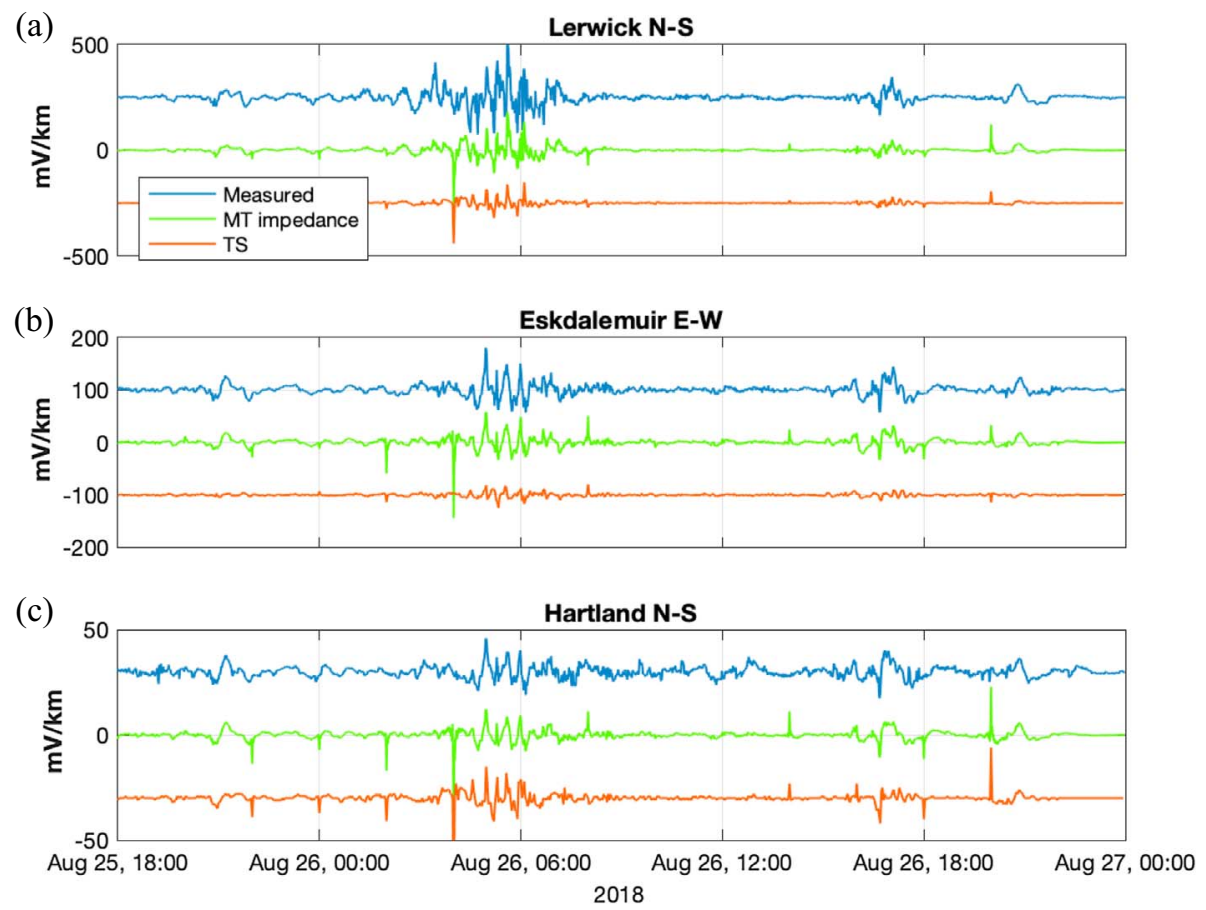

Fig. 10. Comparison of the thin-sheet (TS), magnetotelluric (MT impedance) and measured geoelectric field at (a) Lerwick, (b) Eskdalemuir and (c) Hartland observatories for 26 August 2018. Note only one channel was available at each site.

Table 2. Metric comparisons for three storms with thin-sheet-derived geoelectric field values.

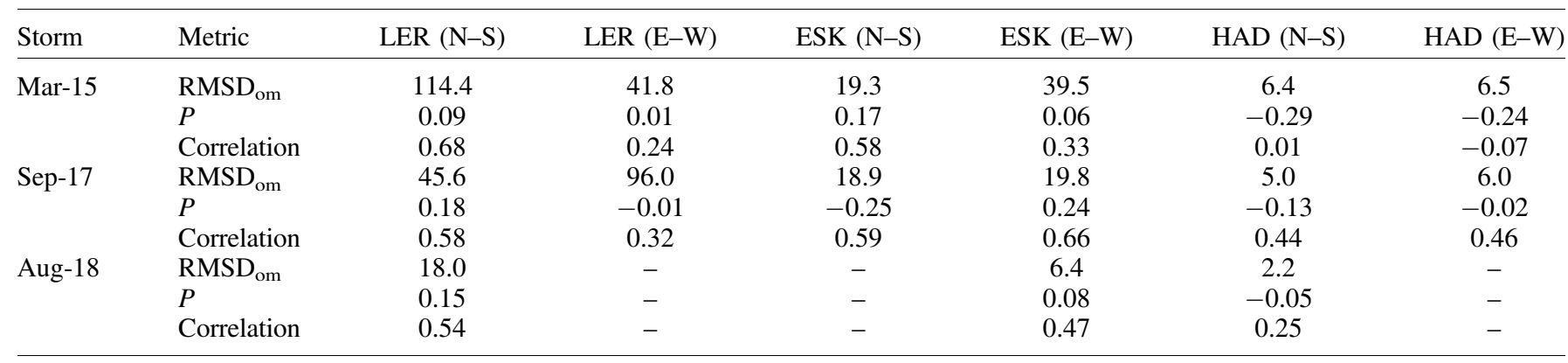

where $\sigma_{o}$ is the standard deviation of the set of observations and $\mathrm{RMSD}_{\mathrm{om}}$ is the root mean square deviation of the residuals (i.e. differences between model predictions and observations),

$$
\mathrm{RMSD}_{\mathrm{om}}=\sqrt{\frac{\sum_{i=1}^{N}\left(o_{i}-m_{i}\right)^{2}}{N}} .
$$

The values $o_{i}$ and $m_{i}$ are the $i$ th point (of $N$ samples) of the observation and model. The maximum value of $P$ cannot exceed 1 where the model exactly fits the observations. However, if $P$ is zero or less there is little direct predictive power, though a negative value of $P$ does not necessarily imply an anti-correlation. Torta et al. (2014) examined time-series of GIC measurements versus GIC models in the Spanish power transmission grid and found that rarely did $P$ exceed 0.4 , even with visually close match between their time-series.

Table 2 gives a series of metrics for the correlation of the measured data and thin-sheet time-series shown in Figures 8-10. For the March 2015 storm, the correlation is surprisingly high for the north-south component of Lerwick and Eskdalemuir at 0.68 and 0.58 , but is around zero for Hartland. The $P$ values for Lerwick and Eskdalemuir are very small though (0.09 and 0.17).

The September 2017 storm shows again that the correlation can be high though the $P$ metric is negative. For Eskdalemuir in the N-S component, there is a good match between the time-series but it has a $P$ value of -0.25 with a correlation of 0.59 . Finally, the thin-sheet electric field estimates for the August 2018 storm are moderately correlated for Lerwick (0.54) and Eskdalemuir (0.47) but low for Hartland (0.25). 
Table 3. Metric comparisons for three storms with the impedance-derived geoelectric field values.

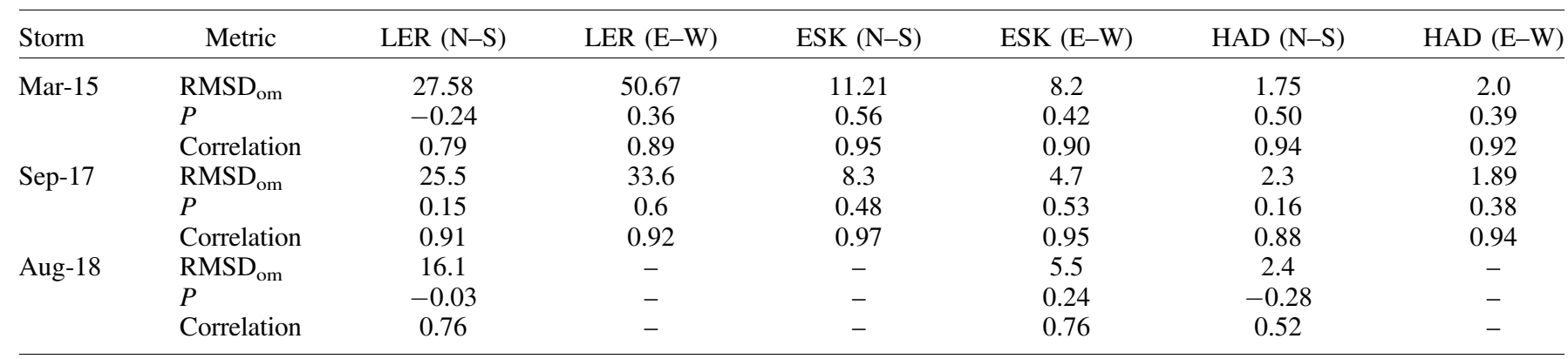

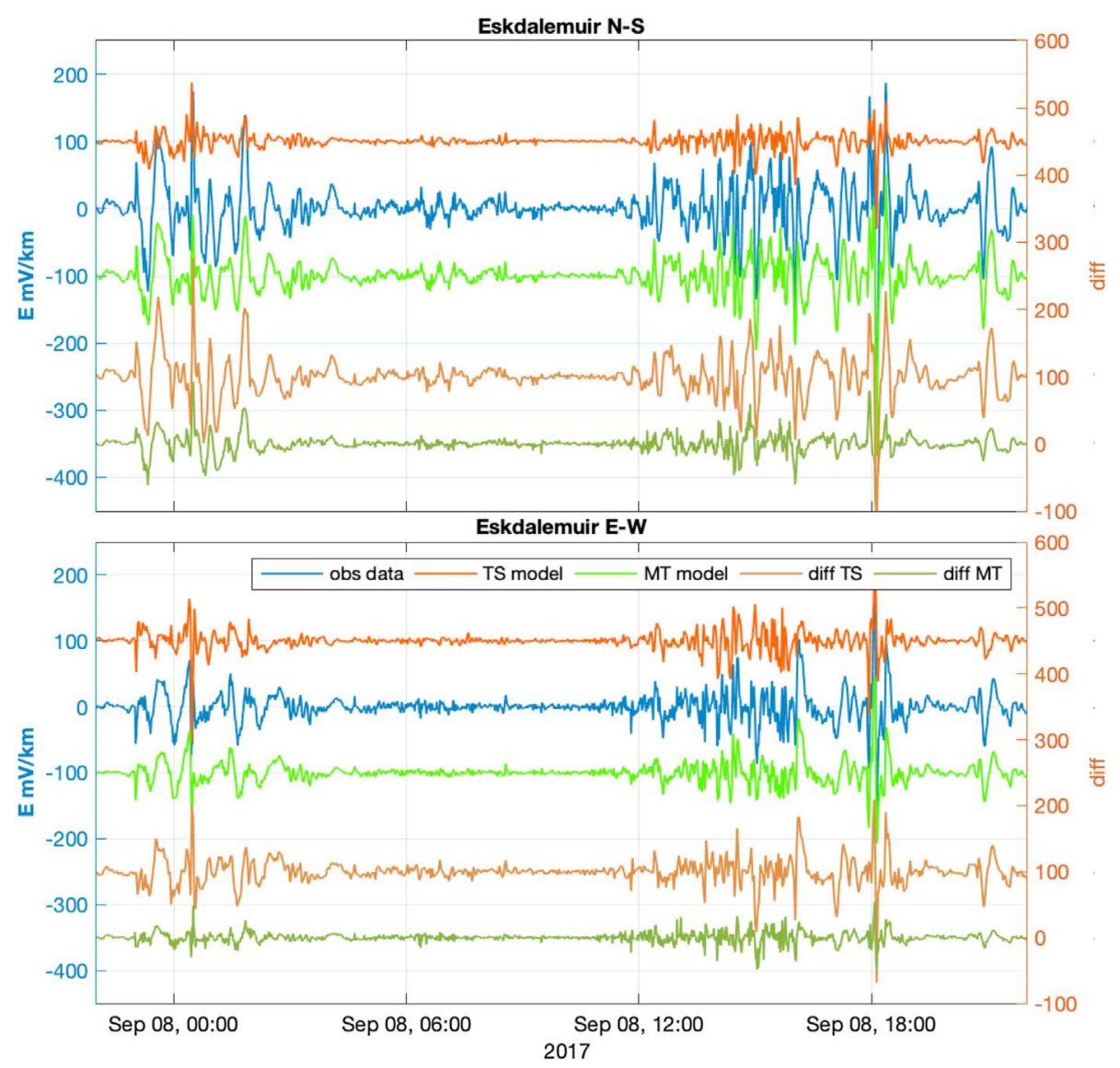

Fig. 11. The measured geoelectric field (blue, offset from zero) and differences between it and the thin-sheet (red) and magnetotelluric (green) models at ESK for the 7-8 September 2017.

For the MT-derived geoelectric field time-series, the correlations with the measured values are given in Table 3. Again, the correlations with each observatory are very high (generally 0.75-0.95), as expected, as the impedance functions are derived from the measurements at each site. However, the $P$ values are quite mixed from -0.24 at Lerwick for the March 2015 storm to 0.56 for Eskdalemuir during the same storm. Hence, even if the correlation is high, the time-series can also have a low $P$ value when there is a large difference in the magnitude.

The differences between the measurements and models can be large and occasionally similar in magnitude. The metric tables illustrate this point - that the correlation between the models can be good but the $P$ metric is often not high and occasionally close to zero. a direct comparison of the models and measurements is shown in Figure 11. The differences between the measured values of the geoelectric field and those modelled by thin-sheet and MT method for the 7/8th September 2017 at Eskdalemuir are plotted. The north-south direction of the thin-sheet model has a negative $P$ value $(-0.25)$ even though the correlation is quite high (0.59) (see Fig. 9). In contrast, the east-west component has $P$ value of 0.24 with a correlation of 0.66 . This is an example where the phase of the 
Thin Sheet model for March 1989

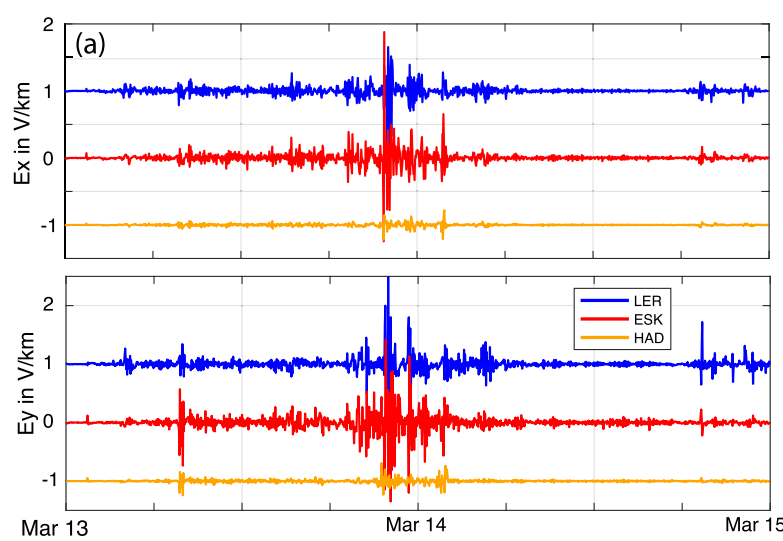

Thin Sheet model for October 2003
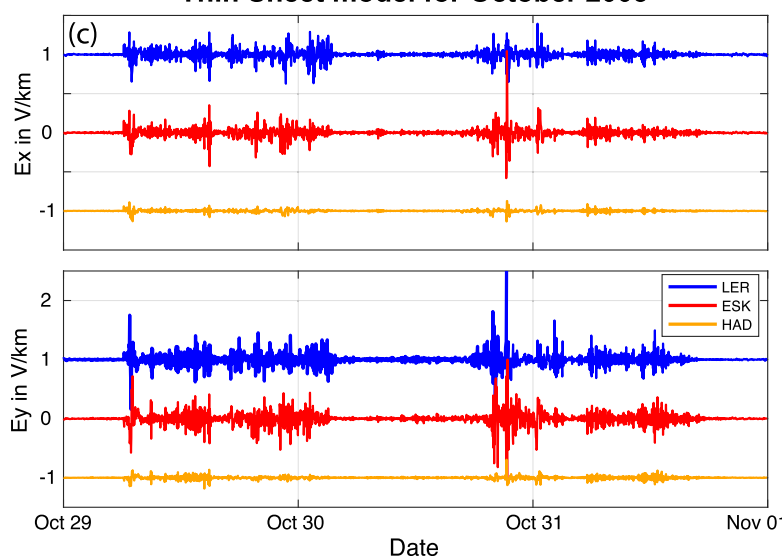

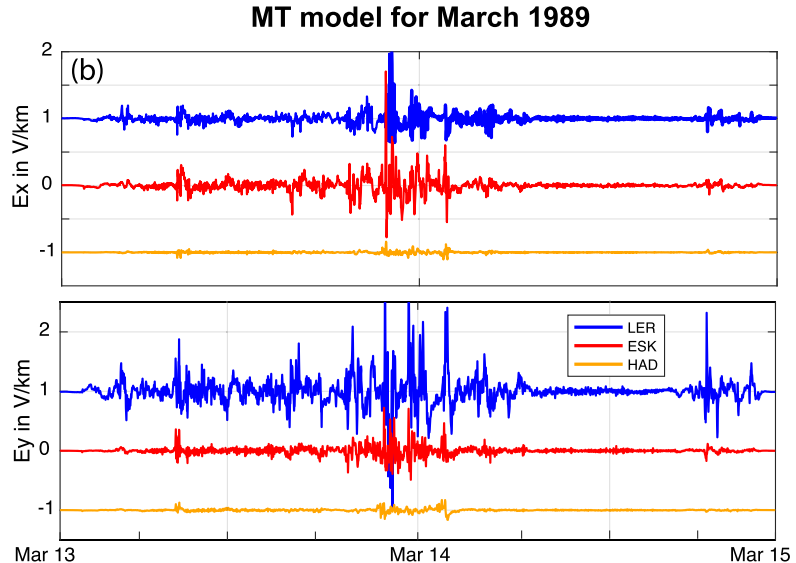

MT model for October 2003

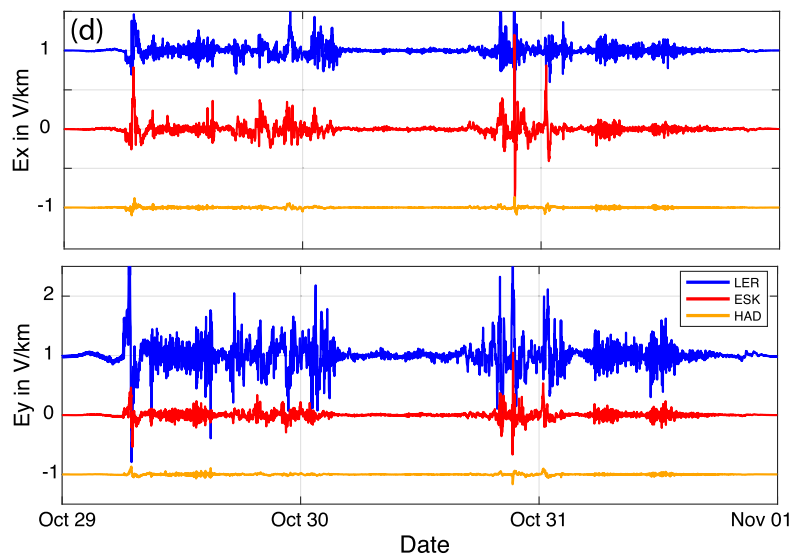

Fig. 12. Upper (a, b): Predicted geoelectric fields for the March 1989 storm. Lower (c, d): Predicted geoelectric fields for the October 2003 storm.

geoelectric field variation is well captured by both models, but the magnitude is not.

\section{Historic storms}

Using the MT impedance functions for each site, the oneminute-mean magnetic field measurements from the 13-14 March 1989 to 29-31 October 2003 were used to estimate the geoelectric field (Campanya et al., 2019; Hübert et al., 2020). The main limitation of this approach is the plane-wave assumption of the magnetic field for the MT response functions, which is generally applicable only for geomagnetically quiet times at mid to low latitudes.

Figure 12 shows the geoelectric field values for both storms computed from the MT impedance and the thin-sheet modelling code. For the thin-sheet model, fewer observatory data were available compared to the analyses in Section 4 (see Table 1) so the magnetic field is not as well captured across the region. For the MT-derived values, the March 1989 storm has electric field amplitudes of up to $1 \mathrm{~V} / \mathrm{km}$ at Lerwick in the north-south component, around midnight on $13 \mathrm{March}$, and $2.3 \mathrm{~V} / \mathrm{km}$ in the east-west component. The north-south component at Eskdalemuir shows a maximum value of $1.7 \mathrm{~V} / \mathrm{km}$ around this time as well, though the fields are smaller $(0.75 \mathrm{~V} / \mathrm{km})$ in the east-west component. The geoelectric field at Hartland does not exceed $0.16 \mathrm{~V} / \mathrm{km}$. The thin-sheet model shows similar magnitude peaks though generally around 30\% lower (e.g. $0.7 \mathrm{~V} / \mathrm{km}$ compared to $1 \mathrm{~V} / \mathrm{km}$ in Lerwick north component).

For the October 2003 storm, the estimated geoelectric fields overall are slightly smaller. Eskdalemuir experienced larger values in the north-south component compared to Lerwick late on the 30th October with one large period of almost $3 \mathrm{~V} / \mathrm{km}$. The larger magnetic (and hence geoelectric) fields experienced at Eskdalemuir in the north-south component may be related to rapid expansion of the auroral oval during storm times (Freeman et al., 2019). The geoelectric field values for Hartland are generally small for both storms and indeed not much larger than those measured during the September 2017 storm for example.

\section{Discussion}

Measurements of the magnetic and geoelectric field at the three UK observatories illustrate that the Earth acts as a highpass filter during geomagnetic storms, removing much of the long magnetic field period variation beyond $1 \mathrm{~h}$. Between 2012 and 2020, the maximum absolute value of the 
geoelectric field recorded was around $1 \mathrm{~V} / \mathrm{km}$ at the Lerwick observatory, while at Eskdalemuir $0.5 \mathrm{~V} / \mathrm{km}$ was measured. Only at Hartland is the geoelectric field visibly dominated by a long-period tidal signal generated by seawater flow in the Bristol Channel.

By combining the geoelectric and magnetic field measurements at the observatories, MT impedance tensors can be computed which provide estimates of geoelectric fields during the large geomagnetic storms, for example, those of March 1989 and October 2003. The MT-derived geoelectric values have a maximum of around $3 \mathrm{~V} / \mathrm{km}$ at Eskdalemuir for the October 2003 storm. However, GIC measurements at the time suggest the geoelectric field was likely to have been even larger. Thomson et al. (2005) show GIC data measured at Torness substation which imply the geoelectric field was between 3 and 4 $\mathrm{V} / \mathrm{km}$ at the peak of the 2003 storm as currents of 20 A were recorded (at a one-second cadence). Recent work on validation of the high voltage network model at Torness in Hübert et al. (2020) corroborates well with this analysis. Given the limited number of large storms in the period of 2012-2020 when geoelectric field data are available to create the impedance functions, the estimates shown here should be considered as a lower bound of the geoelectric field generated during extreme space weather events. We also note that only minute-mean data of historic magnetic field data are available, which reduces the peak magnitude modelled during these storms because the energy content of the higher frequencies is not included.

The comparison of the modelled geoelectric fields from the thin-sheet model with the measured data shows an imperfect match. This is not unexpected, given the limitations of the modelling technique and the input assumptions regarding the underlying geology as a contribution to the electrical conductivity model and variation of the magnetic data across the region. The advantages of using the thin-sheet model, however, include the ability to use snapshot maps of the magnetic field variation both spatially and temporally and the reasonably quick computation time. Providing the spatial variation of the geoelectric field is necessary for modelling GICs in the grounded infrastructure. The quick computation time also allows the thin-sheet model to be used as a real-time now-cast system and as a forecasting tool, assuming suitable estimates of the magnetic field are available. Increasing the number of variometers in the region supplying real-time data would also be very useful in improving the geoelectric field estimate.

Finally, the metrics in Section 5.4 illustrate the problems of the various approximations within the thin-sheet model. In general, the larger the magnitude of the geoelectric field, the better the model matches. It is also worth noting that September 2017 is best modelled because of the denser spatial coverage of observatory and variometer data to create a good representation of the magnetic field. It is also of note that the MT-derived field values have a generally high correlation but a wide range of $P$ values which indicates that $P$ is sensitive to small levels of noise or magnitude differences between time-series.

On-going and future work within the UK NERC-funded SWIGS and SWIMMR projects will provide an island-wide MT survey, at a resolution of around $70 \mathrm{~km}$, similar to the EarthScope project in the USA. We also plan to install new variometers at three further sites in the UK to improve spatial coverage. From these new datasets, we will be able improve the modelling of geoelectric fields across the UK for space weather purposes in a similar manner to Marshall et al. (2019) and Lucas et al. (2020).

\section{Conclusions}

The geoelectric field is a key driver of geomagnetically induced currents in grounded infrastructure. Successfully modelling this field is essential for providing real-time estimates of hazard to the high voltage power network. Due to the diverse geological and topographical structure of the UK, the geoelectric field varies in a complex manner, both spatially and temporally.

We describe the three main strands of research to understand and model the geoelectric field in the UK during severe space weather events. Firstly, continuous measurements of the geoelectric field at a cadence of $10 \mathrm{~Hz}$ have been on-going at the three UK observatories since 2012. Although several major storms have been observed between 2012 and 2020, none have been large enough to cause known issues with technical infrastructure. The largest absolute magnitude of the geoelectric field measured was around $1 \mathrm{~V} / \mathrm{km}$ at Lerwick in March 2015.

Magnetotelluric impedance functions are computed from the geoelectric field and magnetic measurements at the three observatories allowing an estimate to be made of the geoelectric field during past storms such as the March 1989 and October 2003 storms. However, we find that MT transfer functions computed from quiet time tend to underestimate the magnitude of the geoelectric field during storm times.

Modelling using the thin-sheet methodology allows us to compute near-real-time estimates of the field though at the cost of reduced accuracy. From comparison with geoelectric measurements at three observatories, we conclude the thin-sheet model provides some predictive power, though this is typically an underestimate of the true value of the geoelectric field.

Future work will involve updating the geoelectric probes at each observatory as the original hardware reaches the end-oflife, installing new variometers in the UK and to continue to collect magnetotelluric data from sites around Britain to aid the modelling of geoelectric fields for real-time and forecasting applications.

Acknowledgements. We wish to acknowledge the Geomagnetism engineering team (Chris Turbitt, Simon Flower, Tom Martyn, Tony Swan, Tom Shanahan and Tim Taylor) for installing and maintaining the geoelectric field probes at the three BGS observatories. Geoelectric field data were processed as part of an MSc. by Research at the University of Edinburgh by $\mathrm{O}$. Baillie. The results presented in this paper rely on data collected at magnetic observatories. We thank the national institutes that support them and INTERMAGNET for promoting high standards of magnetic observatory practice (https://www.intermagnet.org). We also thank the providers of variometer data in Ireland, Faroe Islands, Norway and the UK. Real-time geoelectric field data are available at http://www. geomag.bgs.ac.uk/data_service/space_weather/geoelectric.html. This work is funded under UK Natural Environment Research Council Grant NE/P017231/1 "Space Weather Impact on Ground-based Systems (SWIGS)". This work has also received 
funding from the European Union's Horizon 2020 research and innovation program under grant agreement No. 870405 (EUHFORIA 2.0). Thin-sheet model outputs are available at the BGS National Geoscience Data Centre. Torness GIC data are available on request from Scottish Power Ltd. We thank the reviewers and the editors for their constructive comments which improved the quality of the manuscript. This paper is published with the permission of the Executive Director of the British Geological Survey (UKRI). The editor thanks Ari Viljanen and two anonymous reviewers for their assistance in evaluating this paper.

\section{References}

Ádám A, Prácser E, Wesztergom V. 2012. Estimation of the electric resistivity distribution (EURHOM) in the European lithosphere in the frame of the EURISGIC WP2 project. Acta Geod Geoph Hung 47(4): 377-387. https://doi.org/10.1556/AGeod.47.2012.4.1.

Albertson VD, Kappenman JG, Mohan N, Skarbakka GA. 1981. Load-flow studies in the presence of geomagnetically-induced currents. IEEE Trans Power Appar Syst PAS-100(2): 594-607. https://doi.org/10.1109/TPAS.1981.316916.

Amm O. 1997. Ionospheric elementary current systems in spherical coordinates and their application. J Geomag Geoelectr 49: 947-955. https://doi.org/10.5636/jgg.49.947.

Bailey RL, Halbedl TS, Schattauer I, Römer A, Achleitner G, Beggan CD, Wesztergom V, Egli R, Leonhardt R. 2017. Modelling geomagnetically induced currents in midlatitude Central Europe using a thin-sheet approach. Ann Geophys 35(3): 751-761. https://doi.org/10.5194/angeo-35-751-2017.

Bailey RL, Halbedl TS, Schattauer I, Achleitner G, Leonhardt R. 2018. Validating GIC models with measurements in Austria: Evaluation of accuracy and sensitivity to input parameters. Space Weather 16(7): 887-902. https://doi.org/10.1029/2018SW001842.

Banks R, Beamish D, Geake M. 1983. Magnetic variation anomalies in northern England and southern Scotland. Nature 303: 516-518. https://doi.org/10.1038/303516a0.

Banks R, Livelybrooks D, Jones P, Longstaff R. 1996. Causes of high crustal conductivity beneath the Iapetus suture zone in Great Britain. Geophys J Int 124: 43-455. https://doi.org/10.1111/ j.1365-246X.1996.tb07031.x.

Beamish D. 2013. The bedrock electrical conductivity map of the UK. J Appl Geophys 96: 87-97. https://doi.org/10.1016/ j.jappgeo.2013.06.001.

Beamish D, White J. 2012. Mapping and predicting electrical conductivity variations across southern England using airborne electromagnetic data. Quart J Eng Geol Hydrogeol 35: 99-110. https://doi.org/10.1144/1470-9236/11-026.

Beamish D, Clark T, Clarke E, Thomson A. 2002. Geomagnetically induced currents in the UK: Geomagnetic variations and surface electric fields. J Atmos Sol-Terr Phys 64(16): 1779-1792. https://doi.org/10.1016/s1364-6826(02)00127-x.

Beggan C. 2015. Sensitivity of geomagnetically induced currents to varying auroral electrojet and conductivity models. Earth Planets Space 67(1): 1-12. https://doi.org/10.1186/s40623-014-0168-9.

Beggan CD, Marple SR. 2018. Building a Raspberry Pi school magnetometer network in the UK. Geosci Commun 1(1): 25-34. https://doi.org/10.5194/gc-1-25-2018.

Beggan CD, Beamish D, Richards A, Kelly GS, Thomson AWP. 2013. Prediction of extreme geomagnetically induced currents in the UK high-voltage network. Space Weather 11: 407-419. https://doi.org/10.1002/swe.20065.

Blake SP, Gallagher PT, McCauley J, Jones AG, Hogg C, Campanyà J, Beggan CD, Thomson AWP, Kelly GS, Bell D. 2016. Geomagnetically induced currents in the Irish power network during geomagnetic storms. Space Weather 14(12): 1136-1154. https://doi.org/ 10.1002/2016sw001534.

Blake SP, Gallagher PT, Campanyà J, Hogg C, Beggan CD, Thomson AP, Richardson GS, Bell D. 2018. A detailed model of the Irish high voltage power network for simulating GICs. Space Weather 16: 1770-1783. https://doi.org/10.1029/2018SW001926.

Blum CC, White TC, Sauter EA, Stewart DC, Bedrosian PA, Love JJ. 2017. Geoelectric monitoring at the Boulder magnetic observatory. Geosci Instrum Methods Data Syst 6(2): 447-452. https://doi.org/10.5194/gi-6-447-2017.

Bolduc L. 2002. GIC observations and studies in the Hydro-Québec power system. J Atmos Sol-Terr Phys 64: 1793-1802. https://doi. org/10.1016/S1364-6826(02)00128-1.

Bonner LR, Schultz A. 2017. Rapid prediction of electric fields associated with geomagnetically induced currents in the presence of three-dimensional ground structure: Projection of remote magnetic observatory data through magnetotelluric impedance tensors. Space Weather 15: 204-227. https://doi.org/10.1002/ 2016SW001535.

Boteler DH. 2006. The super storms of August/September 1859 and their effects on the telegraph system. Adv Space Res 38(2): 159-172. https://doi.org/10.1016/j.asr.2006.01.013.

Boteler DH. 2019. A 21st century view of the March 1989 magnetic storm. Space Weather 17: 1-15. https://doi.org/10.1029/2019SW002278.

Boteler DH, Pirjola RJ. 1998. The complex-image method for calculating the magnetic and electric fields produced at the surface of the Earth by the auroral electrojet. Geophys J Int 132(1): 31-40. https://doi.org/10.1046/j.1365-246x.1998.00388.x.

Cagniard L. 1953. Basic theory of the magnetotelluric method of geophysical prospecting. Geophysics 18: 605-635. https://doi.org/ 10.1190/1.1437915.

Campanya J, Gallagher PT, Blake SP, Gibbs M, Jackson D, Beggan CD, Richardson GS, Hogg C. 2019. Modeling geoelectric fields in Ireland and the UK for space weather applications. Space Weather 17(2): 216-237. https://doi.org/10.1029/2018SW001999.

Caraballo R, González-Esparza JA, Sergeeva M, Pacheco CR. 2020. First GIC estimates for the Mexican power grid. Space Weather 18 (2): e2019SW002260. https://doi.org/10.1029/2019sw002260.

Case NA, Marple SR, Honary F, Wild JA, Billett DD, Grocott A. 2017. AuroraWatch UK: An automated aurora alert system. Earth and Space Science 4(12): 746-754. https://doi.org/10.1002/ 2017 ea000328.

Chave A, Jones A. 2012. The magnetotelluric method: Theory and practice, Cambridge University Press, Cambridge, UK. https://doi. org/10.1017/CBO9781139020138.

Dimmock AP, Rosenqvist L, Hall J-O, Viljanen A, Yordanova E, Honkonen I, André M, Sjöberg EC. 2019. The GIC and geomagnetic response over Fennoscandia to the 7-8 September 2017 geomagnetic storm. Space Weather 17: 989-1010. https://doi.org/10.1029/2018sw002132.

Divett T, Manus DHM, Richardson GS, Beggan CD, Rodger CJ, Ingham M, Clarke E, Thomson AWP, Dalzell M, Obana Y. 2020. Geomagnetically induced current model validation From New Zealand's South Island. Space Weather 18: e2020SW002.494. https://doi.org/10.1029/2020SW002494.

Fernberg P. 2012. One-dimensional earth resistivity models for selected areas of continental United States and Alaska. Tech. rep., EPRI, Palo Alto, CA. Technical Update 1026430. 
Freeman MP, Forsyth C, Rae IJ. 2019. The influence of substorms on extreme rates of change of the surface horizontal magnetic field in the United Kingdom. Space Weather 17(6): 827-844. https://doi. org/10.1029/2018SW002148.

Fujii I, Ookawa T, Nagamachi S, Owada T. 2015. The characteristics of geoelectric fields at Kakioka, Kanoya, and Memambetsu inferred from voltage measurements during 2000 to 2011. Earth Planets Space 67: 62, 1-17. https://doi.org/10.1186/s40623-015-0241-z.

Hapgood M. 2019. The great storm of May 1921: An exemplar of a dangerous space weather event. Space Weather 17: 950-975. https://doi.org/10.1029/2019sw002195.

Horton R, Boteler D, Overbye TJ, Pirjola R, Dugan RC. 2012. A test case for the calculation of geomagnetically induced currents. IEEE Trans Power Deliv 27(4): 2368-2373. https://doi.org/10.1109/ TPWRD.2012.2206407.

Hübert J, Beggan CD, Richardson GS, Martyn T, Thomson AWP. 2020. Differential magnetometer measurements of geomagnetically induced currents in a complex high voltage network. Space Weather 18(4): e2019SW002421. https://doi.org/10.1029/2019sw002421.

Ivannikova E, Kruglyakov M, Kuvshinov A, Rastätter L, Pulkkinen A. 2018. Regional 3-D modeling of ground electromagnetic field due to realistic geomagnetic disturbances. Space Weather 16(5): 476-500. https://doi.org/10.1002/2017sw001793.

Juusola L, Vanhamäki H, Viljanen A, Smirnov M. 2020. Induced telluric currents play a major role in the interpretation of geomagnetic variations. Ann Geophys 38: 983-998. https://doi. org/10.5194/angeo-38-983-2020.

Kelbert A. 2020. The role of global/regional Earth conductivity models in natural geomagnetic hazard mitigation. Surv Geophys 41(1): 115-166. https://doi.org/10.1007/s10712-019-09579-z.

Kelbert A, Balch CC, Pulkkinen A, Egbert GD, Love JJ, Rigler EJ, Fujii I. 2017. Methodology for time-domain estimation of storm time geoelectric fields using the 3-D magnetotelluric response tensors. Space Weather 15(7): 874-894. https://doi.org/10.1002/ 2017SW001594.

Kelly GS, Viljanen A, Beggan CD, Thomson AWP. 2017. Understanding GIC in the UK and French high-voltage transmission systems during severe magnetic storms. Space Weather 15(1): 99-114. https://doi.org/10.1002/2016SW001469.

Kis A, Koppán A, Lemperger I, Prodán T, Szendröi J, Verö J, Wesztergo V. 2007. Long-term variation of the geoelectric activity index T. Geophys Res 398: C-99.

Love JJ, Lucas GM, Kelbert A, Bedrosian PA. 2018. Geoelectric hazard maps for the Mid-Atlantic United States: 100 year extreme values and the 1989 magnetic storm. Geophys Res Lett 45(1): 5-14. https://doi.org/10.1002/2017GL076042.

Lucas GM, Love JJ, Kelbert A, Bedrosian PA, Rigler EJ. 2020. A 100-year geoelectric hazard analysis for the U.S. high-voltage power grid. Space Weather 18(2): e2019SW002329. https://doi. org/10.1029/2019sw002329.

Mac Manus DH, Rodger CJ, Dalzell M, Thomson AWP, Clilverd MA, Petersen T, Wolf MM, Thomson NR, Divett T. 2017. Long-term geomagnetically induced current observations in New Zealand: Earth return corrections and geomagnetic field driver. Space Weather $\mathbf{1 5}$ (8): 1020-1038. https://doi.org/10.1002/2017SW001635.

Marshall RA, Wang L, Paskos GA, Olivares-Pulido G, Walt TVD, et al. 2019. Modeling geomagnetically induced currents in Australian power networks using different conductivity models. Space Weather 17(5): 727-756. https://doi.org/10.1029/2018sw002047.

McKay A. 2003. Geoelectric fields and geomagnetically induced currents in the United Kingdom. Ph.D. thesis, University of Edinburgh, Edinburgh, UK. http://hdl.handle.net/1842/639.
McLay S, Beggan C. 2010. Interpolation of externally-caused magnetic fields over large sparse arrays using Spherical Elementary Current Systems. Ann Geophys 28: 1795-1805. https://doi. org/10.5194/angeo-28-1795-2010.

Myllys M, Viljanen A, Rui OA, Ohnstad TM. 2014. Geomagnetically induced currents in Norway: The northernmost high-voltage power grid in the world. J Space Weather Space Clim 4: A10. https://doi.org/10.1051/swsc/2014007.

North-American Electric Reliability Corporation. 2016. Project 2013-03 GMD mitigation: Benchmark geomagnetic disturbance event description. Tech. rep. URL https://www.nerc.com/pa/Stand/ Project201303GeomagneticDisturbanceMitigation/Benchmark_Clean_ May12_complete.pdf.

Oughton EJ, Hapgood M, Richardson GS, Beggan CD, Thomson AWP, et al. 2018. A risk assessment framework for the socioeconomic impacts of electricity transmission infrastructure failure due to space weather: An application to the United Kingdom. Risk Anal 38(12): 1-22. https://doi.org/10.1111/risa.13229.

Pokhrel S, Nguyen B, Rodriguez M, Bernabeu E, Simpson JJ. 2018. A finite difference time domain investigation of electric field enhancements along ocean-continent boundaries during space weather events. J Geophys Res Space Phys 123(6): 5033-5046. https://doi.org/10.1029/2017ja024648.

Preece WH. 1882. Earth-currents. Nature 25(639): 289-289. https://doi.org/10.1038/025289c0.

Pulkkinen A, Bernabeu E, Eichner J, Beggan C, Thomson A. 2012. Generation of 100-year geomagnetically induced current scenarios. Space Weather 10(S04): 003. https://doi.org/10.1029/ 2011SW000750.

Robertson K, Thiel S, Meqbel N. 2020. Quality over quantity: on workflow and model space exploration of 3D inversion of MT data. Earth Planets Space 72: 2, 1-22. https://doi.org/10.1186/ s40623-019-1125-4.

Romano G, Balasco M, Lapenna V, Siniscalchi A, Telesca L, Tripaldi S. 2014. On the sensitivity of long-term magnetotelluric monitoring in Southern Italy and source-dependent robust single station transfer function variability. Geophys J Int 197(3): 14251441. https://doi.org/10.1093/gji/ggu083.

Rosenqvist L, Hall JO. 2019. Regional 3-D modeling and verification of geomagnetically induced currents in Sweden. Space Weather 17(1): 27-36. https://doi.org/10.1029/2018sw002084.

Schulte in den Bäumen H, Moran D, Lenzen M, Cairns I, Steenge A. 2014. How severe Space Weather can disrupt global supply chains. Nat Hazards Earth Syst Sci 2: 4463-4486. https://doi.org/ 10.5194/nhessd-2-4463-2014.

Schultz A, Egbert GD, Kelbert A, Peery T, Clote V, Fry B, Erofeeva S. 2006-2018. USArray TA magnetotelluric transfer functions. Tech. rep., Staff of the National Geoelectromagnetic Facility and their Contractors. http://ds.iris.edu/spud/emtf/15050279.

Simpson F, Bahr K. 2005. Practical magnetotellurics, Cambridge University Press, Cambridge.

Simpson F, Bahr K. 2020. Estimating the electric field response to the Halloween 2003 and September 2017 magnetic storms across Scotland using observed geomagnetic fields, magnetotelluric impedances and perturbation tensors. J Space Weather Space Clim 10: 48, 1-10. https://doi.org/10.1051/swsc/2020049.

Simpson F, Bahr K. 2021. Nowcasting and validating Earth's electric-field response to extreme space-weather events using magnetotelluric data: Application to the September 2017 geomagnetic storm and comparison to observed and modelled fields in Scotland. Space Weather 19: e2019SW002432. https://doi.org/ 10.1029/2019SW002432. 
Smirnov M. 2008. Magnetotelluric data processing with a robust statistical procedure having a high breakdown point. Geophys J Int 152(1): 1-7. https://doi.org/10.1046/j.1365-246X.2003.01733.x.

Sokolova EY, Kozyreva OV, Pilipenko VA, Sakharov YA, Epishkin DV. 2019. Space-weather-driven geomagnetic- and telluric-field variability in Northwestern Russia in correlation with geoelectrical structure and currents induced in electric-power grids. Izv Atmos Ocean Phys 55(11): 1639-1658. https://doi.org/10.1134/ s000143381911015x.

Sun R, Balch C. 2019. Comparison between 1-D and 3-D geoelectric field methods to calculate geomagnetically induced currents: A case study. IEEE Trans Power Deliv 34(6): 2163-2172. https://doi.org/10.1109/tpwrd.2019.2905532.

Thébault E, Finlay CC, Beggan CD, Alken P, Aubert J, et al. 2015. International Geomagnetic Reference Field: The 12th generation. Earth Planets Space 67: 79, 1-19. https://doi.org/10.1186/s40623015-0228-9.

Thomson AWP, McKay AJ, Clarke E, Reay SJ. 2005. Surface electric fields and geomagnetically induced currents in the Scottish power grid during the 30 October 2003 geomagnetic storm. Space Weather 3(S11): 002. https://doi.org/10.1029/2005SW000156.
Torta JM, Marsal S, Quintana M. 2014. Assessing the hazard from geomagnetically induced currents to the entire high-voltage power network in Spain. Earth Planets Space 66: 87, 1-17. https://doi. org/10.1186/1880-5981-66-87.

Vasseur G, Weidelt P. 1977. Bimodal electromagnetic induction in non-uniform thin sheets with an application to the northern Pyrenean induction anomaly. Geophys J Int 51: 669-690. https://doi.org/10.1111/j.1365-246X.1977.tb04213.x.

Viljanen A, Pirjola R. 2017. Influence of spatial variations of the geoelectric field on geomagnetically induced currents. J Space Weather Space Clim 7: A22. https://doi.org/10.1051/swsc/2017024.

Viljanen A, Pirjola R, Amm O. 1999. Magnetotelluric source effect due to $3 \mathrm{D}$ ionospheric current systems using the complex image method for 1D conductivity structures. Earth Planets Space 51: 933-945. https://doi.org/10.1186/BF03351564.

Wait J. 1982. Geo-electromagnetism. Elsevier. ISBN 9780127308807. Wu C-C, Liou K, Lepping RP, Hutting L, Plunkett S, Howard RA, Socker D. 2016. The first super geomagnetic storm of solar cycle 24: "The St. Patrick's day event (17 March 2015)". Earth Planets Space 68: 151, 1-12. https://doi.org/10.1186/s40623-0160525-y.

Cite this article as: Beggan CD, Richardson GS, Baillie O, Hübert J \& Thomson AWP, 2021. Geolectric field measurement, modelling and validation during geomagnetic storms in the UK. J. Space Weather Space Clim. 11, 37. https://doi.org/10.1051/swsc/2021022. 